\title{
El manuscrito de las Várias Obras de Duarte Días y la cultura Hispano-portuguesa del Siglo de Oro
}

\author{
Juan LÁZARO BETANCOR \\ Universidad Antonio de Nebrija \\ jlazarob@nebrija.es \\ Óscar PEREA RoDRÍGUEZ \\ University of California, Riverside \\ oscar.perea-rodriguez@ucr.edu
}

\begin{abstract}
RESUMEN
El presente trabajo pretende esclarecer hasta lo posible la figura de Duarte Días, un poco conocido autor luso del siglo XVI que escribió poesía en castellano y en portugués durante la época filipina. Se indaga sobre su biografía y se repasan sus principales trabajos líricos, $L a$ conquista de Granada (1590) y Várias obras em língua portuguesa e castelhana (1592), al tiempo que se presenta un censo de ejemplares de ambas. También se analiza el códice manuscrito que alberga esta última obra, conservado en el Archivo Histórico Nacional de Madrid, en la sección Inquisición, de gran importancia por ser uno de los escasos originales de imprenta que nos quedan. Finalmente, el trabajo presenta las equivalencias de las obras del poemario de Días entre los impresos y el manuscrito, además de la edición de dos poesías inéditas en castellano que contiene este último.
\end{abstract}

Palabras clave: Duarte Días, sonetos, manuscrito de imprenta, épica filipina.

* Este artículo se inscribe en el proyecto de investigación Legitimación del poder, corrientes religiosas y prácticas de piedad en la corona de Castilla, siglos XIII-XVI (DGICYT, HAR2008-04696/HIST), dirigido por la Dra. Isabel Beceiro Pita, del Instituto de Historia (CCHS-CSIC). En nuestro estudio usaremos el sistema de identificación de copias (Manid) y textos (Texid) utilizado por J. Labrador Herraiz y R. A. DiFranco tanto en su monografía de 1993 como en la página web de la Bibliografía de la Poesía Áurea (BIPA): $<$ http://bancroft.berkeley.edu/philobiblon/bipa_es.html $>$ [consultada 2011-05-10] 


\begin{abstract}
This work intends to shed light on Duarte Días, a little-known $16^{\text {th }}$ century Portuguese author who wrote poetry in both Portuguese and Spanish during the reign of King Phillip II. This paper provides a biographical approach and analyses his two main works- La conquista de Granada, 1590, and Várias obras em língua portuguesa e castelhana, 1592-, while at the same time serves as an inventory of printed issues of both books known to date. The paper focuses on the codex of the Várias obras, located in Archivo Histórico Nacional in Madrid, within Inquisition section; its great importance is due to the fact that it is one of the few remaining manuscritos de imprenta, i.e., the manuscript in which the printed edition was based on. Finally, this article also presents the different locations of poems both within the codex and the printed issues of Várias obras, along with the critical edition of two unpublished sonnets in Spanish found within Días' manuscript.
\end{abstract}

Keywords: Duarte Días, sonnets, manuscript, Epic poetry King Phillip II.

Sumario: 1. Un ignoto sonetista trilingüe, 2. Registro de ejemplares de sus obras impresas, 3. El manuscrito con las poesías de Duarte Dias, 4. Correspondencias entre manuscrito e impreso de las Varias obras, 5. Edición de los sonetos inéditos en castellano

En 1578, la inesperada muerte del rey portugués Sebastián I en la batalla de Alcazarquivir abriría dos sendas en el nacionalismo portugués: una conceptual y mitológica y otra eminentemente terrenal, pues al morir sin dejar heredero brotó un sentimiento nacional de orfandad y una evidencia política que la alimentó ${ }^{1}$. En 1580 , el rey Felipe II, aprovechando la coyuntura del tira y afloja sucesorio que se estaba viviendo en el reino vecino tras la muerte del infante don Enrique, ordenó la invasión militar de Portugal reclamando su derecho al trono ${ }^{2}$. La endeble defensa que presentó Portugal en la batalla de Alcántara, bajo las órdenes del infante don Antonio, dejó el camino libre al rey Austria para anexionar Portugal a la corona española ${ }^{3}$. Fue el perfecto abono para que arraigara la leyenda mesiánica de que el rey Sebastián algún día regresaría para rescatar a Portugal del yugo extranjero ${ }^{4}$.

La lectura más importante que cabe hacerse de aquel primer sebastianismo, avanzando un poco más allá de la "national obstinacy" con que fuera definido hace algunos años ${ }^{5}$, es el más que palpable descontento con la situación política de aquel entonces $^{6}$. Mientras muchos portugueses aceptaron la nueva situación de la monarquía dual y entraron a formar parte de la corte española, otros mostraron abierta

1 Además de la reciente biografía del monarca a cargo de A. Villacorta Baños-García, pueden consultarse al respecto las recientes aportaciones del volumen colectivo $O$ Sebastianismo (2004).

${ }^{2}$ Proceso descrito en su tesis doctoral por F. Bouza Álvarez (1987).

${ }^{3}$ Cf. R. Cueto (1992), pp. 150-169.

${ }^{4}$ M. Gandra (1999), pp. 86-87.

${ }^{5}$ M. Brooks (1964), pp. 41-42.

${ }^{6}$ Cf. J. V. Serrão (1994). 
animosidad a Castilla, así que el sebastianismo fue buena leña que echar al fuego nacionalista ${ }^{7}$. Dentro de las lindes lusitanas hubo inflamadas exaltaciones de la lengua portuguesa, como las de Bernardo de Brito, Leitão de Andrade, Manoel de Faria e Sousa, Severim de Faria, o, andando el tiempo, las más delirantes del escritor Sousa de Macedo en sus Flores de España, Excelências de Portugal (1631). Tales fogosidades a mayor gloria de Portugal habría que leerlas exclusivamente en esa clave nacionalista aludida, pues la preeminencia y uso del español fue evidente, aunque sólo se tratara de una cuestión de índole práctica dada su mayor divulgación europea. Dicha situación queda nítidamente acotada por afirmaciones como la de Eugenio Asensio, cuando afirma que a partir de 1580 "lengua, música y poesía se castellanizan, y con todo, jamás hubo época de mayor exaltación nacional"», o la de Glaser, quien tampoco duda en señalar que "demostraban los hombres de letras lusitanos un vivo y firme interés por las corrientes literarias del país vecino"

A quienes se pasaron al lado español se les llamó los "estrangeirados», y posteriormente, los «mal amados», un eufemismo que pretende ocultar el más crudo adjetivo de odiados, que en cuestiones de crítica literaria se tradujo a lo largo del tiempo en el silenciamiento - si no ninguneo absoluto, como ya apuntaba Asensio ${ }^{10}$ - de aquellos escritores lusos que emplearon la lengua castellana como cauce de expresión artística y, aun más «grave» en algunos casos, para alabar las glorias del imperio español ${ }^{11}$. Si bien en la mayoría de ocasiones se trataba nada más que de un ejercicio poético ${ }^{12}$, desde la perspectiva del sebastianismo portugués, los autores que cruzaron a la parte castellana durante la Monarquía Dual pasaron a ser víctimas del más absoluto de los oprobios ${ }^{13}$, al ser estampados con la etiqueta de ese êrro ibérico ${ }^{14}$, con el agravante de que muchos de ellos habían formado parte de los recursos con los que Felipe II procuró que su empresa tuviera éxito también en la guerra de plumas inherente a la invasión de Portugal. ${ }^{15}$

${ }^{7}$ Cf. J. Hermann (1998).

${ }^{8}$ E. Asensio (1949), p. 68.

${ }^{9}$ E. Glaser (1957), p. VIII.

${ }^{10}$ E. Asensio (1949), pp. 75-76.

${ }_{11}^{11}$ Para el contexto histórico, véase F. Bouza Álvarez (1998).

12 Téngase en cuenta, como indica Rösnner (1998), las hazañas del cacique Colocolo cantadas por Ercilla en su poema épico La Araucana, que jamás merecieron reprobación alguna a su autor, sino, antes al contrario, el aplauso de la crítica.

13 "Hay en ciertos libros portugueses una simplificación sentimental de la época filipina que reparte los actores en vendidos y leales, héroes y traidores. Esta visión deforma no sólo la perspectiva histórica, sino también la literaria." E. Asensio (1949), p. 108.

${ }^{14}$ Expresión acuñada por J. de C. Osorio (1942), p. 7.

${ }^{15}$ Parafraseamos el lúcido análisis de esta articulación entre literatura y política en época filipina realizado por F. Bouza Álvarez (2010), pp. 12-15. 


\section{Un ignoto sonetista trilingüe}

Es en el contexto cultural de la España filipina, en pleno epicentro de esa "poética sin límites lingüísticos en los finales del siglo XVI" "16, donde nos encontramos al poeta luso Duarte Días, uno de los literatos que con más empeño buscó en sus escritos alcanzar cuantas más adhesiones mejor a la nueva entidad geopolítica surgida tras las Cortes de Tomar $^{17}$. Pese a ello $-\mathrm{o}$ tal vez habría que decir por ello-, su biografía carece de datos que nos permitan tejer un recorrido cronológico mínimamente fiable, y eso a pesar de que su obra ha suscitado un reciente interés a ambos lados de la raya, con aportaciones como las de José Ares Montes ${ }^{18}$, Helio Alves ${ }^{19}$, y Antonio Cirurgião ${ }^{20}$, editor este último de los sonetos impresos de nuestro autor. Sin embargo, su biografía apenas está documentada y las escasas referencias, al margen de contener algunos errores e incorrecciones, son tenues pinceladas que no terminan de perfilarla.

A Duarte Días, vinculado antaño con la escuela de Sá de Miranda ${ }^{21}$, se le supone venido a Castilla a hacer fortuna como soldado de los ejércitos de Felipe $\mathrm{II}^{22}$, uno de los ámbitos predilectos de aquellas elites portuguesas utilizados por el Rey Prudente y por su hijo y sucesor para vertebrar la sociedad de la nueva nación ibérica ${ }^{23}$. Se ha venido citando a Nicolás Antonio como el que situara primero los orígenes familiares de nuestro poeta en la ciudad de Oporto, pero tal noticia no es del todo correcta. En la primera edición de su magna obra, 1672, tan sólo figura un escueto "Edvardvs Diaz, Lusitanus miles" ${ }^{24}$, que acompaña a la noticia de la edición de sus dos obras. No fue sino en la segunda edición de 1783, la manejada con más frecuencia por los investigadores, cuando encontramos añadido a la descripción anterior el gentilicio "Portuensis"25. Otro detalle que no figuraba en la primera edición es el tamaño, octavo, del impreso La conquista de Granada. Como quiera que esta segunda edición fue preparada por el erudito valenciano Francisco Pérez Bayer, se debe a él, y no a Nicolás Antonio, el dato de la filiación portuense de Duarte Días. Además, el hecho de que Pérez Bayer también precisara el tamaño de La conquista de Granada nos lleva a sospechar que leyó esta obra, o cuando menos consultó algunos poemas, por lo que intuimos que el editor valenciano extrajo el gentilicio de la misma obra de Días, concretamente del verso "Duarte, que es de Oporto maravilla", que se lee en uno de

${ }^{16} C f$. V. Infantes (2003), p. 185.

${ }_{17}^{17}$ Señalado así por T. Branderberger (2007), p. 87.

${ }^{18}$ J. Ares Montes (1984), pp. 19-36.

${ }^{19}$ H. J. S. Alves (1993), pp. 99-109.

${ }^{20}$ D. Días (1991).

${ }^{21}$ Así lo hizo T. Braga (1871), p. 181.

${ }^{22}$ Siguiendo las noticias del padre de los bibliógrafos portugueses, D. B. Machado (17411754), I, p. 730: “Assistio (sic) muitos anhos em Hespanha com o posto de soldado.” De aquí toman su perfil biográfico tanto I. F. Da Silva (1870), IX, p. 152, como D. G. Peres (1890), pp. 152-153.

${ }^{23}$ Perfectamente estudiado por F. Labrador Arroyo (2006).

${ }^{24} \mathrm{~N}$. Antonio (1672), I, col. 259b.

${ }^{25}$ N. Antonio (1783), I, col. 336a. 
los laudatorios sonetos preliminares de La conquista de Granada ${ }^{26}$. Tradicionalmente, el nacimiento en Oporto de Duarte Días se daba también por verosímil por la amistad que le unió con el gran poeta portuense de la época, Pedro de Andrade Caminha, que dedicó en 1589 a Días un epigrama latino en agradecimiento por haberle este enviado alguna de sus poesías para su lectura ${ }^{27}$. Sin embargo, al margen de esta relación amistosa con Caminha y de la precisión efectuada por Pérez Bayer, no hay más constancia de tal origen que no proceda del verso antes mencionado.

El soneto que contenía ese verso con el gentilicio "de Oporto" salió de la pluma de Pedro Liñán de Riaza, el clérigo bilbilitano integrante del círculo de amigos de Lope de Vega en Toledo ${ }^{28}$, a quien la crítica ha señalado como posible identidad del Avellaneda autor de la apócrifa continuación quijotesca ${ }^{29}$. El poema induce a sopesar la atractiva posibilidad de que el luso y el aragonés se hubieran conocido y tratado personalmente en alguno de los entramados culturales de la época, tal vez en Madrid, refulgente corte de la España de los Austrias ${ }^{30}$, tal vez en Toledo. Pero el caso es que apenas disponemos de datos para aseverar esta relación: téngase en cuenta que renombrados especialistas, como por ejemplo Saraiva y Lopes ${ }^{31}$, o Jorge de Sena ${ }^{32}$, ni siquiera lo mencionan en sus estudios. Incluso la crítica moderna apenas reseña la existencia de alguna de sus obras ${ }^{33}$, en especial La conquista de Granada, por su valor como ejemplo de la poesía épica filipina ${ }^{34}$, o bien se ocupan de algún aspecto menor, como la edición de alguna de sus composiciones ${ }^{35}$, en especial de las complejas sextinas $^{36}$, junto al hecho de perpetuar los escasos y ya esclerotizados datos biográficos de nuestro autor bilingüe $\mathrm{e}^{37}$.

Pese a tan desalentadora falta de noticias y datos biográficos, existe a nuestra disposición una colección de nombres propios en las aprobaciones, dedicatorias,

${ }^{26}$ Puede leerse en P. Liñán de Riaza: Poesías (1982), p. 48.

${ }^{27}$ Cf. C. M. de Vasconcelos (1901), p. 357, n. 3: "Da haben wir, ausser dem Verkehr mit den mehrfach genannten Koryphaen, Austausch von Schriften, z.B. mit Duarte Dias. Der druckte seine Varias obras em portugués e castelhano erst 1592; der 1589 verstorbene Caminha aber dankt ihm für Zusendung von Versen (Epigr. CLXXXVI)".

${ }^{28}$ Amistad destacada por Randolph en su edición de P. Liñán de Riaza (1982), pp. 8-9 y 16-17.

${ }^{29}$ Cf. A. Sánchez Portero (2007), pp. 61-78; y J. L. Pérez López: (2005), pp. 1-60. Ambos artículos se encuentran disponibles en Internet a través de este enlace: $<$ http://parnaseo.uv.es/lemir.htm>

${ }^{30}$ Cuyo entorno ha estudiado S. Martínez Hernández (2010), pp. 35-67.

${ }^{31}$ Se limitan a añadir el nombre de Duarte Días y la referencia de Cirurgião en una adenda bibliográfica (1973, p. 1192).

${ }_{32}$ Ausencia criticada por J. Ares Montes (1984), p. 19, n. 1.

${ }^{33}$ Por ejemplo, L. Vilà (2009), p. 1081.

${ }^{34} C f$. L. Vilà (2003), p. 139.

35 Edita la sextina de Duarte Días dedicada a la monumental ciudad de Cartago J. Carvalho (2003), pp. 34-35.

${ }^{36} \mathrm{Cf}$. A. Cirurgião (1992), pp. 143-154.

37 Tampoco lo menciona Buescu (2004). 
preliminares y algunos poemas laudatorios de sus dos libros que, cuando menos, pueden darnos una idea de los círculos sociales en los que pudo moverse Duarte Días para hacer buena la descripción de Machado, que decía de él que "cultivou sempre as Musas, para cuio estudo o inclinou o genio desde pimeira idade" ${ }^{38}$.

En tan mítica fecha como 1580, Alonso de Ercilla, soldado y paje del futuro rey Felipe II y autor del poema épico La Araucana ${ }^{39}$, comenzó a ejercer el oficio de censor de libros por encargo del Consejo de Castilla, y es su nombre el que encontramos en las aprobaciones de ambos volúmenes de Duarte Días en 1590 y 1592. A Ercilla, maestro y amigo ${ }^{40}$, lo conoció y lo trató con frecuencia nuestro poeta en el Madrid de la década de $1580^{41}$, tal como se desprende del sentido soneto que le dedica suplicándole despacho y colaboración:
O si acaso la queja que despide una alma portuguesa, puede tanto que castellanas almas enternezca: presteza el corazón os ruega y pide por que, saliendo el esperado canto, a la presencia de mi Sol me ofrezca ${ }^{42}$.

El poema épico La conquista de Granada aparece dedicado a un personaje bien conocido de la época: Cristóbal de Moura, autoproclamado como defensor de la nación portuguesa en Castilla ${ }^{43}$. Nacido en Lisboa en 1538, pasó a Castilla al servicio del rey Felipe II. Su lealtad y buen servicio le valieron para ser nombrado Conde de Castel-Rodrigo, Sumiller de Corps, Camarero Mayor, Comendador Mayor de Alcántara (orden en la que ingresó en 1560), consejero de Estado, embajador en

${ }^{38}$ D. Machado (1741-1754), I, p. 730.

${ }^{39}$ Para la biografía del madrileño, siguen siendo de obligada consulta los trabajos de A. J. Aquila (1975) y F. Pierce (1984). No obstante, ningún dato hemos hallado sobre Duarte Días en estas monografías, salvo que el primero (1975, p. 30) consultó los ejemplares de la BNE de ambas obras de nuestro poeta.

${ }^{40}$ De hecho, a veces se considera a Días un discípulo de Ercilla por la influencia de $L a$ Araucana del segundo en La conquista de Granada del primero. Cf. M. Chevalier (1966), pp. 158-162; y J. Arce (1973), p. 42.

${ }^{41}$ E. Asensio (1949, p. 100) habla de "Ercilla, su maestro y probable amigo", tomando el dato seguramente de D. Peres (1890, p. 152): "Ercilla, que fue su amigo y quizá compañero de armas". Asimismo, en referencia a Alonso de Ercilla, se suele citar a Duarte Días como susceptible de ser uno de sus "amigos portugueses que vivieran en Madrid." $C f$. N. Baranda (2005), p. 231.

${ }^{42}$ Nótese que este soneto, recopilado por el autor en 1592 en Varios poemas $(37 \mathrm{r}-37 \mathrm{v})$, se escribió con el propósito de conseguir que se publicara La conquista de Granada. Por lo tanto, una probable fecha de datación del poema sería 1589, antes del 17 de noviembre, fecha de la aprobación final del libro.

${ }^{43}$ Así lo consideraba su veterano biógrafo, A. Dánvila y Burguero (1900), pp. 706-707, con las noticias más habituales sobre la relación entre Días y Moura. 
Portugal y Virrey de Portugal ${ }^{44}$. Posteriormente, Felipe III le concedió el título de I Marqués de Castel-Rodrigo con Grandeza de España. Nuestro soldado-poeta entró al servicio de tan insigne principal, como lo demuestra su muy revelador soneto titulado "A don Luis Coutinho, a cuya presencia me manda el señor don Cristóbal de Moura" $^{45}$ (fol. 73 r) ${ }^{46}$. En dicho poema, el autor cita también a Margarida Corte Real y Silva, esposa de Cristóbal de Moura, y es a ella a quien dedicó el volumen de Várias obras. Al margen de seguir las modas de la época en cuanto a dedicatorias ${ }^{47}$, sin duda se trató de una gentileza del escritor, como hicieran otros posteriormente ${ }^{48}$, para agradecer el mecenazgo y valimiento que la pareja le había prestado en España, quién sabe si quizá relacionada con esa idea, tan querida de Moura y del mismísimo Felipe II, según la cual "los poetas suelen ser buenos espías"

La relación de Duarte Días con el matrimonio Moura / Corte Real nacería a través de la vinculación de aquel con otros miembros de la familia de Margarida asentados en Madrid $^{50}$, en especial con el tío de la dama, Jerónimo Corte Real, que aparece relacionado con nuestro poeta en varias ocasiones. Noble, soldado en su juventud y asimismo trovador, sin duda Jerónimo Corte Real fue el precedente directo de Duarte Días por haber compuesto la Austriada, o Felicísima victoria concedida del cielo al señor don Juan de Austria, en el golfo de Lepanto de la poderosa armada otomana, en el año de nuestra salvación de 1572 (BIPA, Texid 89545) ${ }^{51}$, un largo poema épico escrito en castellano y dedicado a loar la gloria del hermano bastardo del emperador

${ }^{44}$ Cargos ya consignados por Machado, (1741-1754), I, p. 730.

${ }^{45}$ Don Luis (Luiz en portugués) Coutinho, se había casado en 1583 con doña Joana da Silva, hija de Vasco Eanes Corte Real y, por tanto, hermana de doña Margarida. Aparece mencionado como "fidalgo cavalleiro" en el Libro de las moradias de los fidalgos de la casa de Felipe I desde 1580. Según dicha relación, en 1597 a este hidalgo le correspondía de pensión 3.900 reales al año y un «alqueire e meio» de cebada al día. (Un alqueire era una antigua medida de capacidad portuguesa equivalente a 13 litros.) Véase F. Labrador Arroyo (2006), pp. 515 y 797.

${ }^{46}$ Siempre nos referimos a la foliación del impreso, para que se puedan localizar nuestras citas tanto en el original como en la edición de Cirurgião.

${ }^{47}$ Explicada por R. Chartier (1996), pp. 81-100.

${ }^{48}$ Nos referimos a Fray Pedro de Vega, que también dedicó a la Marquesa de CastelRodrigo su Declaración de los siete Psalmos penitenciales en sus tres primeras impresiones: Alcalá: Juan Íñíguez de Lequerica, 1599 (BNE, R/31017), Madrid: Luis Sánchez y Miguel Serrano de Vargas, 1602-1603 (BNE, 3/73960) y Zaragoza: Carlos de Lanagen, 1606 (BNE, $\mathrm{R} / 24019)$.

${ }^{49}$ Recogido por F. Bouza Álvarez (2010), p. 11.

50 De este entorno también debió de formar parte Juan de Corte Real, presbítero del Colegio Imperial. Cf. M. Agulló y Cobo (1969), p. 202.

${ }^{51}$ Impreso en Lisboa por Antonio Ribero en 1578. Al margen del ejemplar que hemos manejado de la BNE, R/3738 (BIPA, Manid 1258), tenemos constancia de otro albergado en la Biblioteca de la Universidad de Valencia (Z-7/167). Cf. A. Gisbert Terol y M. L. Ortells Pérez (1992), I, pp. 351-352, nº 1081. 
Carlos $\mathrm{V}^{52}$. El círculo continúa con el hecho de que Alonso de Ercilla fuera quien concediese la licencia de impresión en 1594 a la traducción castellana de Sucesso do Segundo Cerco de Diu, de Jerónimo Corte-Real, cerrándose en este caso con la mención admirativa que nuestro poeta realizó en su obra sobre la conquista granadina de quien debió de ser uno de sus grandes ejemplos: "Corte Real, / gloria de Apolo, luz de Portugal" ${ }^{53}$.

Durante su estancia en el ejército, al margen de servirle para aprender las otras lenguas en las que escribiría sus obras ${ }^{54}$, parece que Días trabó entrañable y profunda amistad con los maeses de campo Luis Enríquez y Pero Bermúdez Santisso, según se desprende de los poemas que les dedicó. A Luis Enríquez van destinados dos sonetos ("Aquí se despidió la triste Nida", fols. 9r-9v; y "Mucho la burla moderada agrada", fols. 22r-22v) y unas Estancias, o leyes contra los mirones (fols. 18v-21v). El tono distendido en que están compuestos estos poemas, una curiosa parodia de temas "a lo divino" "55, más el hecho de que a su vez dedicara otro soneto a la esposa de este, Mariana Enríquez ("A un retrato de la señora doña Mariana Enríquez", fol. 12r), hace pensar que el trato entre ambos soldados era íntimo y fraternal. Al otro maese de Campo, "el amado Bermudes" (fol. 41r), van dirigidas dos sentidas elegías a su muerte, "La vida del maese de campo Pero Bermúdez de Santisso" (fols. 23v-26v) y "Carta al maese de campo Pero Bermúdez de Santisso" (fols. 40v-43r). Con todo, la relación entre el poeta y Pero Bermúdez está todavía por explorar, pues el largo poema titulado Discurso sobre as cousas dos soldados, que comienza con el verso "Senhor Pedro Bermudes, pois a guerra" (fols. 62r-65v), permanece aún inédito.

Por estas últimas alusiones podemos concretar que Duarte Días era un gran conocedor de la vida soldadesca. Y como tomándose un respiro en la temática clásica que suele abordar en su poesía, compone unos versos de cierto corte humorístico en los que aconseja no comprar un caballo sin antes verlo en acción. El poema, escrito en portugués y dedicado a don Rodrigo Telo ("A don Rodrigo Telo a hua queda que deu hum Capito de Campanha em hum cavalo que le vendeo", fols. 67r-67v), da noticia de un episodio cómico, como lo es la caída de un caballo de un capitán, que debió de ser mofa y comidilla en el cuartel.

El círculo de amistades de Duarte Días se ve ampliado en otra elegía, "Carta a Pedraires Victória" (fols. 70r-71v), en la cual Duarte se retrata como su "estrecho amigo", su "dulce compañero" y "secretario de sus pensamientos". A la luz de alguno de sus sentidos versos, sin duda la amistad entre ambos debió de ser estrecha:

${ }^{52}$ Cf. L. Vilà (2004), pp. 75-90.

53 Tomamos ambas noticias de H. J. S. Alves: «Apresentação» a Jerónimo Corte-Real: Poesia (1998), pp. XIX-XX.

54 Machado (1741-1754), I, p. 730: "Soube com perfeição a lingua castelhana e teve bastante noticia da italiana." Es probable que los dos sonetos trilingües (portugués, castellano e italiano) del poemario sean parte de una moda literaria de la época: en los mismos años, el petrarquista Francisco de Terrazas utiliza con profusión idénticos artificios. $C f$. Á. Bustos Táuler (2003), pp. 5-19.

${ }^{55}$ Cf. F. J. Sánchez Martínez (1999), pp. 280-281. 
Da sagrada amisade (só movido de quanto mereceis) vos dedicou o nome, a vida, o gosto, a alma, a pena (fol. $70 \mathrm{r})^{56}$.

Al gobernador Pero Gedes le dedica Duarte Días otra larga tirada de versos en "Carta" (fols. 4r-7r) ${ }^{57}$. Se trata de tercetos encadenados, en arte mayor, que hablan de los trabajos de la vida, la fugacidad del tiempo y otras reflexiones morales en la misma línea. No hay, como en prácticamente ninguno de sus poemas, referencias personales que aporten un fragmento de tangible realidad a la biografía de Duarte Días.

Tan sólo encontramos dos excepciones: en el soneto dedicado a un hidalgo "que debía de resto de una moneda de cierto trigo" (fol. 36v) y en el soneto que le sigue, dedicado al sochantre Afonso Ferraz, "para ser terceiro com este fidalgo" (fol. 37r), en el que Días le ruega al eclesiástico que interceda para que se salde con él una deuda. Pese a ser dos poemas llenos de artificio poético, quedan patentes las apreturas económicas de la soldadesca, y en concreto las de nuestro poeta.

También resulta muy ilustrativo el espectro social representado en los preliminares de su otra obra, La conquista de Granada ${ }^{58}$. Muy próximos a la corte o a sus periferias, frailes, autoridades civiles, poetas soldados, licenciados, médicos, tanto portugueses como españoles, le dedican sonetos alabanciosos sin demasiada trascendencia literaria, si bien resultan interesantes para comprobar a quién se dirigió Duarte Días a pedir apoyo para la publicación del libro.

El primer soneto pertenece a la pluma del Fray Pedro de Padilla. Es normal que el carmelita encabece este grupo de poemas, pues no sólo se trataba de un fecundo y renombrado poeta de la época", sino que "por estos años se dedica a traducir obras italianas y a dar la aprobación a muchos libros preparados por amigos suyos ${ }^{\$ 60}$. Ingresó en el convento carmelita de Madrid en $1585^{61}$, de nuevo una fecha muy

56 Algunos detalles más sobre esta relación entre Pedraires y Duarte ofrece F. M. S. Viterbo (1900), pp. 694-696.

${ }^{57}$ Mal citado por Ares Montes (1984, p. 35), que titula el poema "Carta do Governador Pere Guedes." Aparte del error al copiar el nombre del gobernador, se convendrá en que no es lo mismo una Carta de que una Carta al.

${ }^{58}$ Aspecto ya destacado por P. Salvá y Mallen (1872), II, pp. 481-482.

59 Para el Jardín espiritual (1585), su amigo Miguel de Cervantes compuso tres poemas. En "Redondillas al hábito de fray Pedro Padilla", Cervantes comienza con el verso "Hoy el famoso Padilla". Y el propio Cervantes inmortalizó la abrumadora fecundidad de este poeta religioso y profano en el Quijote, pues durante el escrutinio de libros el cura se refiere al voluminoso Thesoro de varias poesías de Padilla (tenía 900 páginas), publicado en 1580: "Como ellas [las poesías de Padilla] no fueran tantas, fueran más estimadas". $C f$. P. Padilla (2008).

${ }^{60} C f$. J. Labrador Herraiz y R. DiFranco (2007), p. 22.

${ }^{61} \mathrm{Cf}$. A. Valladares Reguero (1995), p. 17. 
aproximada a la estancia de Duarte Días en la capital, por lo que no parece aventurado pensar que ambos mantenían una relación de amistad.

Compuso el segundo soneto Liñán de Riaza, que probablemente fue soldado en la jornada de las Azores en 1582, según apunta Eugenio Asensio ${ }^{62}$. Su buen amigo Pedraires Victoria compuso el tercero de los sonetos laudatorios, en el que alaba tanto el estilo como el valor del amigo Duarte. Le siguen don Alonso Fernández de Mesa, el licenciado Manuel Francisco ${ }^{63}$, Francisco Méndez de Medeiros y cierra la serie Pedro de Medina.

Pese a ir su soneto en penúltimo lugar, hemos querido dejar para el final a alguien cuya presencia constituye un hito importante: el doctor Francisco Díaz (1527-1590), "cirujano del Rey nuestro Señor" y padre de la urología española ${ }^{64}$. Díaz fue autor del primer tratado de urología en la Historia de la Medicina ${ }^{65}$, además de protagonizar un suceso muy famoso en la época, como fue intervenir como experto en el proceso inquisitorial contra un presunto hermafrodita acusado por el Santo Oficio de haberse hecho pasar por hombre para casarse con otra mujer ${ }^{66}$. Es obvio que Duarte Días pensó que la reputación y la honorabilidad de este doctor ayudarían a esquivar la censura y conseguir, por fin, la ansiada aprobación que permitiera la impresión de $L a$ conquista de Granada, al margen de que ambos pudieran conocerse de las operaciones militares de los años 1582 y 1583, en las que Díaz actuó como médico de campaña y donde ambos tal vez hubiera podido compartir su común afición por la poesía $^{67}$.

A partir de la época de impresión de su obra no conocemos apenas noticias de nuestro poeta. Existe un apunte contable en el portugués Libro de las moradias de los fidalgos que menciona a un "Ruy Dias de Menezes, filho de Duarte Dias", en la nómina regia de Felipe II correspondiente a los "fidalgos escudeiros" del año $1587^{68}$; diez años más tarde, la misma fuente se ocupa de un "Nicolao de Carvalho de

${ }^{62}$ E. Asensio (1949), p. 100. ¿Se podría aventurar que Liñán de Riaza y Duarte Días se conocieron en dicha jornada luchando en el mismo bando bajo bandera del rey de España y Portugal, Felipe II, frente a la flota francesa, y que a partir de entonces Duarte Días pasó a España? De ser así, en algún momento a partir de 1583 nuestro poeta ya fuera visto en tierras españolas.

63 Seguramente este Manuel, o Manoel, Francisco sea el mismo autor de otro soneto encomiástico en la obra del portugués Enrique Garcés, explorador de las tierras del Perú y también ocasional poeta. Cf. G. Lohmann Villena (1948), p. 478, n. 65.

${ }^{64}$ Así lo considera E. Maganto Pavón (1993), pp. 3-12.

${ }^{65}$ Al margen de los dos ejemplares del tratado de Díaz (1588) que hemos consultado (BNE, R/16563 y R/30641) y de la edición facsímil (1968), la obra ha sido recientemente digitalizada por Google Books y puesta a libre disposición en Internet:

$<$ http://books.google.com/ebooks/reader?id=7Xk0AAAAMAAJ\&hl=ca\&printsec=frontc over\&output=reader $>$ [consultada 2011-05-10]

${ }^{66}$ E. Maganto Pavón (2007), pp. 873-886.

${ }^{67}$ Es la hipótesis de E. Maganto Pavón (2009), pp. 35-105.

${ }^{68}$ F. Labrador Arroyo (2006), II, p. 515. 
Menezes", también hijo de Duarte Días ${ }^{69}$, con idéntica valía económica y asimismo en el ámbito de los escuderos portugueses de la corte filipina. Sin embargo, este personaje ha sido identificado como Duarte Días de Meneses, el famoso secretario del rey Sebastián fallecido en Alcazarquivir en 1578, que estuvo casado con Beatriz Carvalho y fue padre, en efecto, de ambos sirvientes áulicos ${ }^{70}$. Resulta asimismo complicado pensar que otro Duarte Días, cantor de la capilla de Felipe II durante aquellos mismos años ${ }^{71}$, sea el hombre que buscamos, pues la biografía cortesana y musical de este último le aleja, en principio, de los parámetros biográficos de armas, batallas y lírica épica que, con toda certeza, hay que aplicar al autor que analizamos. Por si fuera poco, existe otro Duarte Días, maestre portugués fallecido hacia 1611, a quien hemos encontrado solicitando ayuda al cabildo de Tortosa en 1597 para representar una obra de teatro ${ }^{72}$. Sospechamos que este último, establecido en tierras tarraconenses, es el mismo autor de un epigrama latino en alabanza a su antiguo amigo, el presbítero Joan Dessí, insertado en los preliminares de la obra de aquel, la Divina semana (BIPA, Texid 70280$)^{73}$, un poema épico en octava rima sobre la creación del mundo impreso en $1610^{74}$, que es a su vez traducción del original francés, La Première Sepmaine ${ }^{75}$. La hipótesis de que el portugués Duarte Días, soldado y poeta de la época filipina, hubiera acabado, treinta años después, retirado en Cataluña, aunque todavía interesado en aspectos líricos y culturales, es bastante atractiva y podría ser factible, pero en la actualidad carecemos de pruebas que la confirmen.

Y es que, en realidad, los únicos datos seguros que conocemos de él no sólo nos lo muestran bastante lejos de Tarragona, establecido en Madrid, sino que además arrojan ciertas dudas sobre su origen portuense. En un documento del 10 de marzo de 1590, Sebastián de Portillo, que actúa como representante legal de la imprenta de la viuda de Alonso Gómez, firma un finiquito de cuentas con "Duarte Díaz", de quien se dice que es "portugués", pero también se le denomina "de Burgos" en el mismo documento. En él, Portillo reconoce haber entregado a "Duarte Díaz" mil quinientos ejemplares de la obra impresa para él, la Conquista de Granada, a cambio de la

${ }^{69}$ Ibid., II, p. 522.

${ }^{70}$ Ibid., II, pp. 745-746.

${ }^{71}$ Manuel Ferreira, mozo de capilla de la casa real lusa en 1593, era hijo del cantor Duarte Días y de Inés de Borges. Cf. F. Labrador Arroyo (2006), II, p. 852.

${ }_{73}^{72}$ Cf. Querol Coll (2001), p. 294.

73 Impreso en Barcelona, Imprenta de Sebastián Matheuad y Lorenço Deu, 1610. Manejamos el ejemplar BNE, R/2405.

74 "Edvardi Diaz lvsitani in laudem avctoris, summi veterisque amici: Fortis prima die aspexit Gallia septem / cuncta quibus rerum condidit Omniparens / at non sola diu gavisa est munere tanto; mox illuxerunt Itala terra tibi. / Utraque debetis Ferranto tu, illa Salusto, / qui vos nobilitam carmine uterque suo, / ne tamen armipotens tantas Hispania laudes / invideat, Dessi docta Thalia facit. / Hebdomadam Hispanis numeris sic scripsit, ut ambae / invideant merito Gallia et Oenotria. / Mincius hinc cesset doctos iactare Poetas / nam quos opponat dives Iberus habet.", fol. VIr.

${ }^{75}$ Cf. C. Barbolani di Montauto (1989), pp. 209-216. 
cantidad de 1.880 reales, según el contrato que ya ambos habían firmado el 23 de noviembre de 1589, y al que se alude en este finiquito ${ }^{76}$. Como quiera que, en efecto, fue la imprenta madrileña de la viuda de Alonso Gómez la que, en el año $1590^{77}$, imprimió en elegantes tomitos de tamaño octavo con encuadernación en pergamino la citada obra de Duarte Días, no cabe ningún género de dudas de que nos hallamos ante nuestro autor. Es obvio que son muy necesarias mayores pesquisas en archivos para arrojar más luz en su apenas pergeñada biografía, especialmente aclarar si ese "de Burgos" al que se refiere el documento se refiere a su origen o a un hipotético lugar de avecindamiento.

En 1610, otro representante de la aurisecular casta de poetas-soldados ibéricos de similar perfil biográfico ${ }^{78}$, el alférez Francisco de Segura, quiso corresponder a Duarte Días la gentileza de que un portugués hubiese narrado las glorias españolas:

He querido pagar a este Reyno el aver dado al mundo al excelente poeta Duarte Núñez (sic) Lusitano, el qual con maravilloso estilo escrivió un poema heroyco, en que trató la restauración de Granada por los Cathólicos Reyes Don Fernando y Doña Ysabel, de gloriosa memoria; y no es mucho que, pues uvo un portugués que cantasse prohezas de castellanos, que aya otro castellano que cante hechos y victorias de Portugueses ${ }^{79}$.

Muy pocos más parecen haberse acordado de Duarte Días desde entonces. Como ya hemos indicado, hasta 1991 no se hizo una reedición de sus Várias obras. Injusto olvido con que se ha tratado, tanto en Portugal como en España, a quien nunca dejó de cantar la belleza de su amada tierra y de propagar gestas lusas, así como ponderar y ensalzar al pueblo español, bien fuese en obras retóricas derivadas de aquella unión ibérica que vivieron ${ }^{80}$, bien fuese mediante la búsqueda de un elogioso pasado común

${ }^{76}$ Resumimos los datos ofrecidos por M. Agulló y Cobo (1992), II, p. 241.

77 Hay una errata en la fecha consignada por Machado (1741-1754, I, p. 730), donde figura "1598" en vez de la correcta "1590".

${ }^{78}$ En especial, con muy fluidas relaciones con Portugal, como denotan sus frecuentes viajes a Lisboa. Véase Antonio Rodríguez-Moñino (1968a), pp. 185-204.

${ }^{79}$ Segura (1610), fols. 7r-v. Hemos manejado el ejemplar conservado en Madrid (BNE, $\mathrm{R} / 7903$ ) para completar la sesgada cita de Asensio (1949, p. 101), quien, por otra parte, pasa por encima sin explicar la confusión que produce aquí el apellido 'Núñez' en vez de 'Días'. Sin duda, Francisco de Segura está pensando en Duarte Días, pero yerra al escribir, pues lo confunde con el también poeta portugués Duarte Núñez, autor de la Genealogía verdadera de los Reyes de Portugal con sus elogios y summario de sus vidas (1590), que también cuenta con un ejemplar en la citada biblioteca matritense que hemos asimismo consultado (BNE, $\mathrm{R} / 19146)$.

${ }^{80}$ Es el caso, entre otros, de la obra de Isidoro Velázquez: La entrada que en el Reino de Portugal hizo la S.C.R.M. de don Philippe, Invictíssimo Rey de las Españas (Lisboa: Manuel de Lyra a costa de Simón López, 1583). Manejamos el ejemplar de la BNE, R/8464, aunque tenemos noticia de otro en la Biblioteca Nacional de México. Cf. J. Ymhoff Cabrera (1996), III, pp. 422-423. 
asumible por ambas entidades históricas ${ }^{81}$. Así pues, haciendo caso de la advertencia de Eugenio Asensio a propósito de la conveniencia de no prejuzgar a posteriori toda esta rica literatura dedicada a crear un sentimiento de unión entre España y Portugal ${ }^{82}$, literatura en líneas generales ignorada por los primeros y denostada por los segundos, es buena hora para volver sobre las obras de este poco conocido poeta.

\section{Registro de ejemplares de sus obras impresas}

El más notable trabajo de Días se titula La conquista que hicieron los poderosos y Católicos Reyes, Don Fernando y Doña Isabel, en el reino de Granada, compuesta en Octava Rima (BIPA, Texid 89693). Estamos ante una obra no demasiado bien considerada por la crítica en líneas generales ${ }^{83}$, quizá porque no sólo recoge los acontecimientos historiográficos sino también algunas leyendas sobre la conquista de amplia circulación en el Siglo de Oro, ${ }^{84}$ pero de dudosa autenticidad. No obstante, algunos críticos sí han destacado la existencia de cierta originalidad lírica en sus versos,${ }^{85}$ en especial por el uso de recursos literarios relacionados con el universo de lo fantástico ${ }^{86}$. Hasta hoy, y salvo error o desconocimiento por nuestra parte, hemos tenido noticia de los siguientes ejemplares:

1) Edimburgo, Biblioteca Nacional de Escocia, BCL.D7219. Ejemplar no consultado.

2) Harvard (Massachusetts), Universidad de Harvard, Houghton Library, PC 5.D5431.590c. Fue donado a la biblioteca por José Carlos Lopes, cuyo nombre aparece en el exlibris frontal. La encuadernación es del siglo XIX, a cargo de Antonio Manuel Fernandes Possas, natural de Oporto. El estado de conservación es muy bueno.

3) Lisboa, Biblioteca Nacional de Portugal, Fundo Geral, L. 3577 P. Ejemplar no consultado.

4) Lisboa, Biblioteca Nacional de Portugal, Impressos Reservados, RES. 5577 P. Ejemplar no consultado ${ }^{87}$.

${ }_{82}^{81}$ Sobre ambos aspectos, véase L. Voigt (2011), pp. 17-41.

82 "Mal podemos ser justos con aquellos hombres si arrancamos de una concepción que no fue la suya. No abusemos de la ventaja que da el nacer tres siglos más tarde y conocer la solución del enigma para imponerles unos principios y un código político que no alcanzaron." E. Asensio (1949), p. 108.

${ }^{83}$ Considerada "producción de escaso mérito que, más que poema, es una crónica rimada" por G. Ticknor (1854), III, p. 499; III, p. 177, n.

${ }^{84}$ Como, entre otras, los desafíos entre Garci Laso de la Vega o el Conde de Tendilla con algunos moros, aprovechados por romances y comedias auriseculares. $C f$. M. Garrido Atienza (1910), p. 103, n. 2.

${ }^{85}$ Es el caso de M. S. Carrasco Urgoiti (1989), pp. 72-73.

${ }^{86} C f$. A. Cirurgião (2002), pp. 85-99.

87 En la misma institución existe un microfilm de uno de los dos ejemplares, sin que podamos precisar de cuál de ellos están tomadas las imágenes. La referencia es Microfilm F. 5185 . 
5) Londres, British Library, 1072.d.5. Con casi toda seguridad, se trata del ejemplar procedente de la biblioteca particular de Sir Thomas Grenville ${ }^{88}$. Conserva la encuadernación original.

6) Londres, British Library, G.10963. De buen estado de conservación en general, sin embargo se encuentra mútilo de la página del título y los dos siguientes folios con la fe de erratas.

7) Los Ángeles (California), Universidad de California en Los Ángeles, Charles E. Young Library, PQ 6388.D542.C7. Ejemplar no consultado.

8) Madrid, Biblioteca Nacional de España (en adelante, BNE), R/8222. ${ }^{89}$ (BIPA, Manid 2185). Posee un exlibris de Fernando José de Velasco, fiscal del senado criminal del reino de Castilla. El estado de conservación es bueno, aunque la encuadernación está rajada por la parte inferior y algunos folios corren el riesgo de desprenderse, sobre todo al principio.

9) Madrid, BNE, R/3271 ${ }^{90}$. Tal como nos informan las iniciales a mano situadas a la izquierda de la portada, este ejemplar perteneció a la biblioteca del conocido bibliófilo Pascual de Gayangos ${ }^{91}$. En la primera parte de la obra existen varias anotaciones manuscritas y referencias a antiguos posesores: Manuel de Prado (fol. 1r), María de Flores, mencionada en un poemita inicial obra seguramente del automencionado Próspero Fernández (fol. guarda). Hay un exlibris arrancado y otro pegado con posterioridad que de forma manuscrita nos indica que el libro fue del enigmático D. A. Mosti ${ }^{92}$.

10) Nueva York, Hispanic Society de América, DP 118 D53 C66 $1590^{93}$. El ejemplar procede de la antigua biblioteca del Marqués de Jerez de los Caballeros $^{94}$, que fue comprada en su integridad por esta institución a

${ }^{88}$ Cf. J. T. Payne y H. Foss (1842), I, p. 201.

89 El ejemplar está microfilmado en la misma Sala Cervantes de la BNE, con signatura R.micro / 23640.

${ }^{90}$ El ejemplar está microfilmado en la propia Sala Cervantes de la BNE, con signatura R.micro / 11546.

${ }^{91}$ En abril de 1891, escribía Gayangos a Menéndez Pelayo: “También he adquirido La conquista de Granada, por el portugués Duarte Días”. Cf. Epistolario de Menéndez Pelayo, vol. 11, carta 150. Acceso en Internet a través de $<$ http://www.larramendi.es/i18n/corpus/unidad.cmd?idCorpus=1002\&idUnidad=1002>.

Recoge la posesión C. Pérez Pastor (1891), p. 169, $\mathrm{n}^{\circ} 327$, si bien toda su información es calcada a la de B. J. Gallardo (1866), II, p. 763, n 2018.

${ }^{92}$ Es frecuente ver aparecer este exlibris, "D.A. Mosti o Mosty", no sólo en la colección de la BNE, sino en otras bibliotecas matritenses. $C f$. "Anteriores poseedores de los ejemplares de la Biblioteca Histórica de la Universidad Complutense", página web $<$ http://www.ucm.es/BUCM/foa/doc17550.pdf > [consultada 2011-05-10]

${ }^{93}$ Hacemos constar nuestro máximo agradecimiento a John O’Neill, bibliotecario jefe de la Hispanic Society, por su ayuda para la localización y consulta de los ejemplares de las obras de nuestro poeta conservados en la institución neoyorquina.

${ }^{94}$ En efecto, el libro figura en el Catálogo de la Biblioteca del Excmo. Sr. D. Manuel Pérez de Guzmán y Boza, Marqués de Jerez de los Caballeros. Primera parte (1898), p. 46. 
comienzos del siglo $\mathrm{XX}^{95}$. Se conserva bastante bien, gracias en parte a su consistente encuadernación en pasta vieja, posiblemente de finales del siglo XVIII. Hay algunas manchas de humedad en la juntura superior de la encuadernación, que se traspasa a alguno de los primeros folios, pero luego va desapareciendo de forma gradual. En el segundo folio de guarda vuelto, justo al lado de la portada inicial, figura el antiguo número de orden de una antigua biblioteca donde esta copia reposó $\left(n^{\circ} 269\right)$, y también una curiosa anotación en portugués, seguramente de un antiguo posesor, que nos informa de lo siguiente:

Este autor foi português porém escreveo em Castellano porque era no reinado de Felipe primeiro Rei de Portugal, e segundo, Rei de Castella.

11) Nueva York, Biblioteca Pública, Rare Book Collection, KB 1590. Encuadernado en piel por la prestigiosa casa J. Mackenzie, el ejemplar perteneció a la Lennox Collection. Al igual que el ejemplar de la Hispanic Society, las dos hojas supuestamente perdidas que describe la catalogación estaban en blanco, por lo que el texto está completo.

Al margen de su Conquista de Granada, el trovador luso afincado en España también publicó un poemario, que es la obra que más nos interesa en este trabajo. Llevó un título muy de moda entre los poetas de la época, especialmente los relacionados con labores militares ${ }^{96}$, como es el de Várias obras de Duarte Díaz, em lingua portuguesa e castelhana, dirigidas a Doña Margarida Corte Real (BIPA, Texid 88289) ${ }^{97}$. Luis Sánchez, en sus afamadas prensas matritenses ${ }^{98}$, famosas por imprimir sin apenas erratas ${ }^{99}$, las publicó en el año $1592^{100}$. De esta edición impresa nos consta hoy día la existencia de los siguientes ejemplares:

1) Londres, British Library, C.125.c.7. Conserva la encuadernación original en piel, aunque con algunos desperfectos, en especial dos cortes superficiales en la contraportada. Al margen de esto, el estado de conservación es bastante bueno,

${ }^{95} C f$. C. L. Penney (1965), p. 170. Aunque la descripción diga que le faltan dos hojas finales, se trata de dos hojas en blanco, no hay ninguna parte de la obra que se haya perdido.

${ }^{96}$ La obra poética de Acuña, editada el año anterior, así lo atestigua. Véase G. Cabello Porras (2008), pp. 5-61.

${ }_{97}^{97}$ Descripción en Gallardo (1866), II, p. 764, nº 2019.

${ }^{98}$ Cf. F. Bouza Álvarez (1997), p. 36.

99 Tal es la opinión de C. del Rivero (1935), pp. 20-21.

${ }^{100}$ De nuevo por errata de imprenta, en D. Machado (1741-1754, I, p. 730) figura el año incorrecto de 1692 para esta edición, en vez del correcto de 1592. 
si bien el ejemplar está incompleto, pues le faltan los dos últimos folios, 74 y $75^{101}$.

2) Madrid, BNE, R/11280 (BIPA, Manid 2064) ${ }^{102}$. El ejemplar, encuadernado en holandesa, perteneció al conocido bibliófilo y erudito del siglo XIX Pascual de Gayangos. Se trata además de un libro muy particular, pues sobre este ejemplar se solicitó licencia y privilegio de impresión, de forma que, entre otras características, carece de tasa, lo que indica que fue el modelo sobre el que se imprimió el resto de la serie ${ }^{103}$. Además, en las dos páginas finales existen notas manuscritas y un listado de erratas rubricado por el conocido Juan Vázquez de Mármol $^{104}$, racionero granadino de origen converso ${ }^{105}$, que fue paleógrafo ${ }^{106}$, erudito y corrector general de libros durante el reinado de Felipe $\mathrm{II}^{107}$. Es lógico suponer que suyas son también las muchas anotaciones de este ejemplar, tanto correcciones como indicaciones sobre la posición que deberían ocupar los poemas en este modelo de impresión ${ }^{108}$.

3) Madrid, Lázaro Galdiano, R 9-14-17 (olim Inv. 9589) ${ }^{109}$. El ejemplar presenta un buen estado de conservación, con una encuadernación en piel marrón del siglo XVII que tal vez proceda de la biblioteca del rey Felipe IV. La presencia de la tasa en la página inicial nos indica que fue uno de los que circularon por el Madrid de la época.

4) New York, Hispanic Society, PQ 9231.D53 A6 1592. Otra vez nos encontramos con un ejemplar procedente de la biblioteca del Marqués de Jerez de los Caballeros ${ }^{110}$, que cuenta con una discreta encuadernación holandesa de pergamino $(198 \times 143)^{11}$. La modestia de este librito se ve también en el uso de

101 Queremos dejar constancia de nuestro máximo agradecimiento a Raika Wokoeck, bibliotecaria de la sección de raros de la British Library, por su impagable ayuda para la localización y descripción de este ejemplar.

${ }^{102}$ El ejemplar está microfilmado en la misma Sala Cervantes de la BNE, con signatura R.micro / 37243.

103 De acuerdo a la Pragmática sobre la impresión de libros, promulgada el 7 de septiembre de 1558, era obligatorio incluir en los preliminares del libro la licencia, la tasa y el privilegio de impresión, este último en caso de haber sido solicitado. $C f$. F. Bouza Álvarez: (2008), pp. 4-7.

${ }^{104}$ Cf. F. Bouza Álvarez: (2002), pp. 19-45.

${ }^{105}$ Cf. M. F. Gómez Vozmediano (2005), p. 53.

${ }^{106}$ Cf. C. Olmedilla Herrero (1993), pp. 191-232.

${ }^{107}$ Cf. F. Bouza Álvarez (1997), pp. 32-37. Más información sobre el oficio de corrector general, en T. González Rolán y P. Saquero Suárez-Somonte (1992), pp. 23-37.

${ }^{108}$ Para la labor del corrector en el ejemplar de Duarte Días, véase F. Bouza Álvarez (2002), pp. 20-21.

${ }^{109}$ Debajo de las signaturas hay una anotación a lápiz de una mano del siglo XX que indica "Imprenta en Madrid, $\mathrm{n}^{\circ}$ 384". Obviamente, se refiere a la catalogación de C. Pérez Pastor (1891), p. 195.

${ }^{110}$ Cf. Catálogo...(1898), p. 46.

${ }^{111}$ Cf. Penney (1965), p. 170. 
un folio impreso del siglo XVIII como hoja de guarda inicial ${ }^{112}$, mientras que otro folio impreso, esta vez de una obra denominada Fructus sanctorum, sirve de hoja de guarda final ${ }^{113}$. El estado de esta copia es bueno, aunque con muchos folios, de tamaño cuarto $(199 \times 135)$, salpicados de las típicas manchas de humedad simplemente debidas al inexorable paso del tiempo. Un antiguo posesor del ejemplar marcó las poesías en lengua castellana, que recordemos son minoritarias al lado de las mayoritarias en portugués, mediante la escritura de una equis o una ce, a la izquierda o a la derecha del primer verso de cada uno de los poemas en castellano, tal vez para localizarlos con más facilidad ${ }^{114}$. Este y otros detalles nos llevan a concretar que el posesor del ejemplar de la Hispanic Society tenía como lengua materna el castellano. Por ejemplo, en el folio 21r, en la estrofa que comienza "Y el mísero momo que estuviere", el autor corrige el margen del verso "el que toque la suerte luego rasa" por "raça". Otro caso de idéntica corrección lo tenemos en el folio 52r, cuando en la estrofa "O bienaventurado...", el autor corrige el margen "y libre de interece", indicando que es una 's' en vez de una 'c' en esta última palabra.

De estas copias conocidas de las Várias obras de Días existen varios microfilmes conservados en distintas bibliotecas norteamericanas, a saber:

a) Ann Arbor (Michigan), Universidad de Michigan, PQ 9231.D53. ${ }^{115}$ Los negativos están tomados del ejemplar de la British Library.

b) Berkeley (California), Universidad de California, signatura Microfilm 14053.PQ. ${ }^{116}$ Los negativos proceden del ejemplar de la Hispanic Society de Nueva York.

c) Boulder (Colorado), Universidad de Colorado, signatura PQ9231.D47 V3 1592a ${ }^{117}$ Los negativos están sacados del ejemplar de la BNE.

d) Evanston (Illinois), Northwestern University, signatura Film 3078. ${ }^{118}$ Los negativos pertenecen igualmente al ejemplar de la BNE.

112 En concreto, una censura y aprobación del abogado sevillano Diego de la Torre y Esquivel, para la impresión de un memorial de agravios presentado por el gremio de los mercaderes al cabildo hispalense en contra de las leyes, supuestamente recién aprobadas, que prohibían la venta al por menor en la ciudad, entre otros aspectos comerciales regulados.

${ }^{113}$ La obra parece ser un recorrido por las obras pías de algunos gobernantes famosos de la historia de Europa. Las dos personalidades que se leen son la cesión de Imberto, príncipe vienés, del Delfinado al heredero de la corona de Francia y el posterior reparto del dinero adquirido a cambio entre los frailes dominicos del convento de León, así como una historia similar relacionada con Giovanni Dándolo y Iacopo Tiépoli, duces de Venecia.

${ }^{114}$ Curiosamente, los dos largos poemas sobre el maestre de campo Pero Bermúdez de Santisso no están marcados con una ce, pese a estar escritos en castellano. Ignoramos la razón y si este hecho pudiera tener que ver con algún antiguo dueño de esta copia.

$115<\mathrm{http} / / /$ www.worldcat.org/oclc/475653420> [consultada 2011-05-10]

$116<$ http://oskicat.berkeley.edu/record=b14460225 S1 $>$ [consultada 2011-05-10]

$117<$ http://libraries.colorado.edu/record $=$ b1750845 S3 $>$ [consultada 2011-05-10] 
Pese a que Machado consignase una segunda edición de estas Várias obras de Duarte Días, impresa en "Çaragoça por Pedro Bermudes 1596" "119 es de dudosa existencia. Hay una errata en el nombre del impresor, puesto que no hubo ningún Pedro Bermúdez o Bermudes en la época que tuviera una imprenta en Zaragoza. Podría tratarse de Pedro Bernuz, impresor activo en la capital aragonesa entre 1552 y 1571, cuando adquirió, junto al librero Bartolomé de Nájera ${ }^{120}$, el taller que había sido a comienzos de la centuria propiedad de Jorge Coci ${ }^{121}$. Pedro Bernuz falleció en 1572, tras lo cual la imprenta fue adquirida por una sociedad tripartita formada por Pedro Sánchez de Ezpeleta, Gabriel de Híjar y Juan de Alteraque ${ }^{122}$, de forma que no parece probable que haya salido bajo adscripción a sus prensas una obra en 1596, o por lo menos no hemos encontrado referencia a ella en el censo de obras impresas en Zaragoza durante el Quinientos ${ }^{123}$.

\section{El manuscrito con las poesías de Duarte Días}

Además de los impresos descritos anteriormente, y tal vez para hacer buena la máxima por la cual la lírica aurisecular circuló mucho más de forma manuscrita que en letras de molde ${ }^{124}$, tenemos la gran suerte de haber conservado un códice con las obras de Días. Aparte de su valor intrínseco como fuente primaria, es además uno de esos escasos y valiosísimos originales de imprenta ${ }^{125}$, es decir, la copia sobre la que se preparó la edición impresa.

El códice se halla en la sección de papeles varios inquisitoriales ${ }^{126}$, concretamente en el apartado de censuras, grupo de documentación que, debido a su carácter misceláneo y un tanto inclasificable dentro de los habituales criterios de clasificación archivísticos, a veces suele deparar este tipo de sorpresas. De hecho, en el interior del legajo 4514 encontramos los informes y censuras de otras obras más modernas, como la Historia civil de España desde 1700 a 1733, de Fray Nicolás de Jesús Belando (exp. 2), así como la prohibición de algunos romances, tales como el Santíssimo desposorio de Christo en 1792 (exp. 6), o el Nuevo romance de la embajada que envió el Rey de Inglaterra al de Marruecos en 1780 (exp. 7). Las censuras que rodean

\footnotetext{
${ }^{118}<$ http://nucat.library.northwestern.edu/cgi-bin/Pwebrecon.cgi?BBID=2170927> [consultada 2011-05-10]

${ }^{119}$ Machado (1741-1754), I, p. 730.

${ }_{120}^{12}$ M. J. Pedraza Gracia (1997), pp. 29-52.

${ }^{121}$ Cf. F. J. Norton (1978), p. 220.

${ }_{122}$ Pedraza Gracia (1997), p. 32.

${ }^{123}$ Hemos consultado el veterano mas aún útil recuento de J. M. Sánchez (1914) sin encontrar rastro de esta obra.

124 Expresada por el maestro Antonio Rodríguez-Moñino (1968a), pp. 12-16. Más información en la obra de F. Bouza Álvarez (2001).

125 Véase P. A. Escapa et al.(2000), p. 62. Más información del mismo, en S. Garza Merino (2005).

${ }^{126}$ F. Bouza Álvarez (2002), p. 20, n. 10.
} 
a nuestro códice también tienen por objeto el teatro, ya que se hallan informes negativos para los entremeses Las siete estrellas de Francia (exp. 9) o El cura de Madridejos (exp. 8).

Sin embargo, basta con abrir el voluminoso legajo para tomar conciencia de que el numerado como expediente número 3 no es ningún expediente inquisitorial al uso, sino un manuscrito encuadernado en pergamino $(290 \times 205 \mathrm{~mm})$ sin ninguna indicación exterior. Al abrir la primera página, sin embargo, queda claro que se trata de las Varias obras de Duarte Díaz, dirigidas a doña Margarida Corte Real (fol. 1r), esta vez con el título en castellano. Tanto en la encuadernación de pergamino como en el primer folio del manuscrito hay una signatura antigua, "Manuscritos $n^{\circ} 52$ ", de mano posterior, que pudiera señalar que en un primer momento el códice estuvo incluido en la sección de manuscritos del propio AHN. Nos resuelve el misterio una nueva indicación en la portada de libro: un número, $19195^{3}$, escrito a lápiz en la esquina superior derecha, aunque muy difuminado por el transcurso de los años. Se trata de la signatura que el manuscrito poseía en su antigua procedencia, que no es otra sino la Biblioteca Nacional de Madrid, tal como ya indicaba Paz y Melia en su veterano estudio $^{127}$.

El códice tiene 79 folios, numerados en arábigos en la esquina superior derecha, con letra de la misma mano que el texto. En ocasiones aparecen otras foliaciones tachadas, tanto anteriores como posteriores. Entre otros ejemplos, en el fol. 5r aparece tachado [22], en el 6r está tachado [23], en el 7r [24] y en el 8r [25], lo que implica que este pliego de cuatro folios se añadió con posterioridad. Todo esto es una buena prueba de que el manuscrito era el cuaderno de trabajo de Duarte Días. Además, casi al final del códice pasamos del folio 72 al 74; como explicaremos más adelante, no se trata de un fallo en la numeración, sino de que el folio 73 se ha perdido, de ahí que hoy día tenga 79 folios, y no los 80 que tenía cuando lo examinó Paz y Melia a comienzos del siglo $\mathrm{XX}^{128}$. La encuadernación es muy débil en esta parte final, por lo que la hipótesis de la pérdida de uno de los folios es muy plausible. A pesar de que el estado del códice es, en líneas generales, bueno, hay algunas manchas de humedad muy visibles, por ejemplo, en el folio 7.

El tamaño de los folios carece de regularidad, puesto que el manuscrito se ha coleccionado añadiendo pliegos de diversa procedencia. Así, tenemos folios de $272 \times 189 \mathrm{~mm}$ (fol. $12 \mathrm{r}$ ), de $273 \times 193 \mathrm{~mm}$ (fol. $35 \mathrm{r}$ ) y de $270 \times 195 \mathrm{~mm}$ (fol. $65 \mathrm{r}$ ). La caja de escritura también es ciertamente desigual, oscilando entre los $229 \times 139 \mathrm{~mm}$ (fol. 12r), a 209×135 mm (fol. 35r), hasta un tamaño intermedio de $219 \times 100 \mathrm{~mm}$ (fol. 65r). Las líneas de esta caja de escritura también presentan notable variación: si bien en la parte inicial parecen tener cierta regularidad, ( 25 en el fol. $12 \mathrm{r}$ y 24 en el fol. $35 \mathrm{r}$ ), al final se van ampliando hasta llegar a las 27 del fol. $65 \mathrm{r}$.

Como manuscrito de imprenta, es interesante destacar que cada poema, a veces al inicio, a veces al final, tiene la indicación del cuaderno en que debería ir en el libro impreso, así como el folio en que debía de acabar. La mayoría de las indicaciones, en

${ }^{127}$ Cf. A. Paz y Melia (1914), no 312.

${ }^{128}$ Paz y Melia (1914), n 312, apud P. A. Escapa et al. (2000), p. 62. 
efecto, corresponden a la situación de ese poema en el impreso, por lo que no hay duda de que nos encontramos delante del manuscrito que sirvió de base a los cajistas de la imprenta. No obstante, es bien posible que esta disposición final fuese debida al impresor, ya que el códice parece guardar más bien una ordenación génerica y estrófica, acorde con los poemarios manuscritos de esta época ${ }^{129}$. Y es que, en efecto, la sombra del autor a veces se pierde en el original desde el momento de la primera copia $^{130}$.

Otro rasgo que nos indica que nos hallamos ante un manuscrito de imprenta es la presencia, en el último folio, de la firma de Juan Gallo de Andrada, el conocido escribano del Consejo de Castilla y de la Cámara de Felipe II, encargado, entre los años finales del siglo XVI y principios del XVII, de consignar las tasas de la mayor parte de libros impresos en la Corona ${ }^{131}$. Aunque de origen burgalés, ${ }^{132}$ Gallo de Andrada debió de residir en la corte, entre Madrid y Valladolid ${ }^{133}$, durante el apogeo cortesano de ambas villas acontecido en los reinados de Felipe II y de Felipe III ${ }^{134}$, por lo que es casi seguro que conoció a Duarte Días, al margen de evaluar su manuscrito para que sus obras fueran impresas.

Por lo que respecta a la letra del códice, se trata de una caligrafía humanística vulgar del siglo XVI, muy legible, redonda y bien trazada, como corresponde a un manuscrito de imprenta. Hay dos tipos de letra: una descuidada que escribe deprisa, visible en los folios $1-26 \mathrm{v}, 30 \mathrm{v}-35 \mathrm{v}, 37 \mathrm{v}-39 \mathrm{v}, 40 \mathrm{v}, 42 \mathrm{r}-55 \mathrm{v}, 60 \mathrm{r}-61 \mathrm{v}$ y $68 \mathrm{r}-80 \mathrm{v}$; una segunda, muy cuidada, caligráfica y con adornos en el trazo, se puede ver en los folios 27r-30v, 36r-37v, 40r-40v, 41r-41v, 56r-59v y 62r-67v. Podemos avanzar una teoría al respecto de estas dos diferentes manos, debido a una coincidencia, ya que en el mismo Archivo Histórico Nacional, dentro de la sección de Diversos, se han conservado sendos testimonios manuscritos de dos poemas de Duarte Días contenidos en su poemario: en primer lugar, ${ }^{135}$ el soneto Hermosa dama, que de la ansia mía ${ }^{136}$;

${ }^{129}$ En la línea de lo expuesto por V. Núñez: (1996-1997), pp. 162-163.

${ }^{130}$ S. Garza Merino (2009), p. 119.

131 Incluida la que fue sin duda más famosa de cuantas escribió: la del Quijote de Cervantes. Véase F. Sevilla Arroyo (2009), pp. 362-363. Más noticias de su labor, en P. A. Escapa et al. (2000), pp. 35-37; y en F. Bouza Álvarez (2008), passim.

${ }^{132} \mathrm{Su}$ padre, Antón Gallo, era natural de Burgos, tal como lo especifica en su testamento, fechado en 1534 y conservado en el Archivo General de Simancas, Consejo Real de Castilla, legajo 680, exp. 10.

133 Varios documentos relacionados con su familia nos permiten suponer su avecindamiento en Madrid al menos entre 1562 y 1567. Cf. Agulló y Cobo (1969), pp. 213214.

${ }^{134}$ Precisamente en la urbe pucelana, el escribano de cámara compró la llamada Casa de los Gallo, hoy conocida por ser la sede del Hotel Imperial. Cf. J. Urrea (1996), p. 223.

135 AHN, Diversos, Colecciones, 17, n. 1538. La imagen de este testimonio está disponible en Internet mediante libre acceso, consultando el catálogo de PARES: $<$ http://pares.mcu.es/>

${ }^{136}$ BIPA, texid 36980. 
en segundo lugar ${ }^{137}$, el soneto que envió nuestro autor a Alonso de Ercilla solicitándole premura para la edición de su obra ${ }^{138}$. Al estar estos dos poemitas firmados de puño y letra por Duarte Días, observamos que su caligrafía coincide con la primera del manuscrito, a la que hemos calificado como descuidada y escrita de forma apresurada. Además, la presencia en las dos últimas páginas del impreso de las Várias obras albergado en la BNE de la fe de erratas, firmada por Juan Vázquez del Mármol, nos hace sospechar que la forma caligráfica cuidada y adornada del resto del manuscrito correspondería al citado corrector, si bien se trata de una hipótesis todavía por confirmar.

\section{Correspondencias entre manuscrito e impreso de las Várias obras ${ }^{139}$}

\begin{tabular}{|l|l|l|l|}
\hline PRIMER VERSO & MANUSCRITO & IMPRESO & BIPA TEXID \\
\hline Ditosa Margarida en quem recolhe & $1 \mathrm{r}$ & $1 \mathrm{r}$ & \\
\hline Eis-me aqui outra vez praias do Tejo & $1 \mathrm{v}$ & $1 \mathrm{v}$ & \\
\hline Em quanto os rios para o mar correrem & $1 \mathrm{v}-2 \mathrm{r}$ & $1 \mathrm{v}-2 \mathrm{r}$ & \\
\hline Parte-se o gosto meu parte-se a vida & $2 \mathrm{v}$ & $2 \mathrm{r}$ & \\
\hline O ser da vossa musa soberana & $3 \mathrm{r}$ & $2 \mathrm{v}$ & \\
\hline Tanto pregoa o céu de Rafaela & $3 \mathrm{r}-3 \mathrm{v}$ & $2 \mathrm{v}-3 \mathrm{r}$ & \\
\hline Acaso triste caminhando hum dia & $3 \mathrm{v}-4 \mathrm{r}$ & & \\
\hline Hum peito acompahando de receo & $4 \mathrm{r}$ & $3 \mathrm{r}-3 \mathrm{v}$ & \\
\hline Aqui vede señora a vida cega & $4 \mathrm{v}$ & $3 \mathrm{v}$ & \\
\hline Parece-me señor esto hé verdade & $5 \mathrm{r}-8 \mathrm{v}$ & $4 \mathrm{r}-7 \mathrm{r}$ & \\
\hline De varios pensamentos combatido & $9 \mathrm{r}$ & & \\
\hline Pois se chegan os dias linda dama & $9 \mathrm{v}$ & $7 \mathrm{r}$ & \\
\hline Estrema dor estremo sentimento & $10 \mathrm{r}$ & $7 \mathrm{v}$ & \\
\hline Quando la bella Aurora descubría & $10 \mathrm{r}-10 \mathrm{v}$ & $7 \mathrm{v}-8 \mathrm{r}$ & 42422 \\
\hline A tanto me chegou amor tirano & $10 \mathrm{v}$ & $8 \mathrm{r}$ & \\
\hline Se de tao singular merescimento & $11 \mathrm{r}$ & $8 \mathrm{v}$ & \\
\hline Valerosa señor a quien se debe & $11 \mathrm{r}-11 \mathrm{v}$ & $8 \mathrm{v}-9 \mathrm{r}$ & 45969 \\
\hline Aquí se despidió la triste Nida & $11 \mathrm{v}$ & $9 \mathrm{r}-9 \mathrm{v}$ & 30324 \\
\hline
\end{tabular}

137 AHN, Diversos, Colecciones, 17, n. 1539. La imagen de este testimonio está disponible en Internet mediante libre acceso, consultando el catálogo de PARES: $<$ http://pares.mcu.es/>

${ }_{138}^{138}$ BIPA, texid 44211.

${ }^{139}$ En redonda hemos dejado las composiciones en portugués, por ser las más numerosas. En cursiva, las castellanas, marcando con negrita las dos inéditas que editamos al final de este artículo. Por último, en subrayado aparecen las compuestas parcialmente en italiano. No recogemos las poesías de Duarte Días en los preliminares del impreso de la BNE, que nos ha servido de referencia. Tomamos el encabezamiento de los versos del manuscrito, lo cual a veces puede presentar alguna discrepancia gráfica con el encabezamiento del impreso, pero lo hacemos así a propósito precisamente para facilitar la comparación entre ambos. 


\begin{tabular}{|c|c|c|c|}
\hline Nao me quexo de amor em que reparte & $12 \mathrm{r}-12 \mathrm{v}$ & $9 \mathrm{v}-10 \mathrm{v}$ & \\
\hline Ya cerca de la muerte está la vida & $13 r$ & & \\
\hline Nao sao estos os ryos doce amigo & $13 r-13 v$ & $10 \mathrm{v}$ & \\
\hline Maravilhame muito o novo viso & $13 \mathrm{v}$ & $11 \mathrm{r}$ & \\
\hline Dizer poeta de gastada vea & $14 \mathrm{r}$ & $11 \mathrm{r}-11 \mathrm{v}$ & \\
\hline Pragentas almas que em mor desmetidas & $14 \mathrm{r}-14 \mathrm{v}$ & & \\
\hline Doce esperança pretensao perdida & $14 \mathrm{v}$ & $11 \mathrm{v}$ & \\
\hline O ymagen celeste bela e pura & $15 \mathrm{r}$ & $12 \mathrm{r}$ & \\
\hline Lasso ebe el core a mando se consume & $15 \mathrm{r}-15 \mathrm{v}$ & $12 \mathrm{r}-12 \mathrm{v}$ & \\
\hline E si vuol veder como sagita amore & $15 \mathrm{v}$ & $12 \mathrm{v}$ & \\
\hline O tu aquem o ceo tem concedido & $16 \mathrm{r}-16 \mathrm{v}$ & $13 r-14 r$ & \\
\hline Se eu dise en presum cousa que ofenda & $17 \mathrm{r}-17 \mathrm{v}$ & $14 \mathrm{r}-14 \mathrm{v}$ & \\
\hline Ja he rota a coluna eo verde lauro & $18 \mathrm{r}$ & $15 r$ & \\
\hline O rigurosa morte, o morte dura & $18 \mathrm{r}-18 \mathrm{v}$ & & \\
\hline Y de eborosa rima ha sepultura & $18 \mathrm{v}$ & $15 \mathrm{r}-15 \mathrm{v}$ & \\
\hline O celos del amante horrible freno & $19 \mathrm{r}$ & $15 \mathrm{v}$ & 69915 \\
\hline Quando em conversaçao suave e rica & $19 \mathrm{r}-19 \mathrm{v}$ & $16 \mathrm{r}$ & \\
\hline Nao sao estes señora os lacos de ouro & $19 \mathrm{v}$ & $16 \mathrm{r}-16 \mathrm{v}$ & \\
\hline Matante que buscais as escondidas & $20 \mathrm{r}$ & $16 \mathrm{v}$ & \\
\hline Suave Pedro o vosso entendimento & $20 r-20 v$ & $17 \mathrm{r}$ & \\
\hline En un jardin de flores vi una rosa & $20 \mathrm{v}$ & $17 \mathrm{r}-17 \mathrm{v}$ & 35616 \\
\hline Eu suço e ynda mal por que se forçado & $21 \mathrm{r}$ & $17 \mathrm{v}$ & \\
\hline Calava o mar, calava o fero vento & $21 \mathrm{r}-21 \mathrm{v}$ & $17 \mathrm{v}-18 \mathrm{r}$ & \\
\hline Logrando estou señora ura vrando viso & $21 \mathrm{v}$ & $18 \mathrm{r}-18 \mathrm{v}$ & \\
\hline Claro señor de la decima esphera & $22 r-24 v$ & $18 \mathrm{v}-21 \mathrm{v}$ & 31603 \\
\hline Vendo o cruel amor quanto creçia & $25 r$ & $21 \mathrm{v}$ & \\
\hline Comigo recolhido e pensativo & $25 \mathrm{r}-25 \mathrm{v}$ & $22 r$ & \\
\hline Branca tumor de terra a cor da rosa & $25 \mathrm{v}$ & & \\
\hline Mucho la burla moderada agrada & $26 \mathrm{r}$ & $22 \mathrm{r}-22 \mathrm{v}$ & 38791 \\
\hline Hermosa dama que de la ansia mía & $26 r-26 v$ & $22 v-23 r$ & 36980 \\
\hline Tamanha dor tormentos tao estranhos & $26 \mathrm{v}$ & $23 r$ & \\
\hline Vana esperanca, pretencion dañosa & $27 r-30 r$ & $23 \mathrm{v}-26 \mathrm{v}$ & 45994 \\
\hline Brando señor espirito delicado & $30 \mathrm{v}$ & $26 \mathrm{v}-27 \mathrm{r}$ & \\
\hline Em tanto que o cabelo de ouro fino & $30 \mathrm{v}$ & $27 \mathrm{r}$ & \\
\hline Se de contino en lagrimas banhado ${ }^{140}$ & $31 r-31 v$ & $27 r-28 r$ & 87716 \\
\hline Se hum desigual e ciego pensamento & $32 \mathrm{r}-32 \mathrm{v}$ & $28 \mathrm{r}-29 \mathrm{r}$ & \\
\hline
\end{tabular}

${ }^{140}$ A pesar de estar registrado con Texid en BIPA, el poema está en portugués; lo que sí está en castellano es la rúbrica del mismo: "Agena. Yo me lo sé el porqué, mas no lo digo. Glosa." Al glosar un dicho, el poeta quiere dejar claro que no es suyo, sino de otro, lo que nos indica que nos encontramos con claridad ante un manuscrito de autor. 


\begin{tabular}{|l|l|l|l|}
\hline Pois ques minha ventiera & $33 \mathrm{r}-33 \mathrm{v}$ & $29 \mathrm{r}-30 \mathrm{v}$ & \\
\hline Novo deseyo estranha fantesia & $34 \mathrm{r}-37 \mathrm{v}$ & $30 \mathrm{v}-34 \mathrm{r}$ & \\
\hline No trabalho se mostra e reconhece & $37 \mathrm{v}$ & $34 \mathrm{r}-34 \mathrm{v}$ & \\
\hline Tarda de manera o prato & $38 \mathrm{r}$ & $34 \mathrm{v}-35 \mathrm{r}$ & \\
\hline De quantas mostras eu vy & $38 \mathrm{v}$ & $35 \mathrm{r}-35 \mathrm{v}$ & \\
\hline Sou hua árvore batida & $39 \mathrm{r}$ & $35 \mathrm{v}-36 \mathrm{r}$ & \\
\hline Es tal la pena crecida & $39 \mathrm{v}$ & $36 \mathrm{r}-36 \mathrm{v}$ & 69356 \\
\hline Quanto pode ventura quanto erra & $40 \mathrm{r}$ & $36 \mathrm{v}$ & \\
\hline Nos trances sem remedio quando a vida & $40 \mathrm{r}-40 \mathrm{v}$ & $37 \mathrm{r}$ & \\
\hline Si en el gallardo pecho castellano & $40 \mathrm{v}$ & $37 \mathrm{r}-37 \mathrm{v}$ & 44211 \\
\hline $\begin{array}{l}\text { Daime ca hum rey que tenha quanto } \\
\text { cerra }\end{array}$ & $41 \mathrm{r}$ & $37 \mathrm{v}-38 \mathrm{r}$ & \\
\hline Se passa anossa vida como sombra & $41 \mathrm{r}-41 \mathrm{v}$ & $38 \mathrm{r}$ & \\
\hline Cansado ya de sono en que deseança & $41 \mathrm{v}$ & & \\
\hline Nao se passaron mais alegres dias & $42 \mathrm{r}-43 \mathrm{r}$ & $38 \mathrm{r}-40 \mathrm{r}$ & \\
\hline Eu menina paser em viso e festa & $43 \mathrm{v}$ & $40 \mathrm{r}$ & \\
\hline Eu menina paser em novo pranto & $43 \mathrm{v}$ & $40 \mathrm{v}$ & \\
\hline $\begin{array}{l}\text { Puesto que vuestra ausencia aya } \\
\text { llevado }\end{array}$ & $44 \mathrm{r}-46 \mathrm{v}$ & $40 \mathrm{v}-43 \mathrm{r}$ & 42111 \\
\hline Quando comigo pinto & $46 \mathrm{v}$ & $43 \mathrm{r}$ & \\
\hline Era quasi acabada a minha flama & $47 \mathrm{r}$ & $43 \mathrm{r}-$ & \\
\hline Bem se pode ver no pato & $48 \mathrm{r}$ & & \\
\hline En viendo esa perficcion & $48 \mathrm{r}-48 \mathrm{v}$ & $44 \mathrm{r}-45 \mathrm{r}$ & 69322 \\
\hline Pues que de la prisión estraña y larga & $49 \mathrm{r}-49 \mathrm{v}$ & $45 \mathrm{r}-46 \mathrm{r}$ & 70102 \\
\hline Se o tomo que recolhe & $50 \mathrm{r}-52 \mathrm{r}$ & $46 \mathrm{r}-47 \mathrm{v}$ & \\
\hline Se não poems Amaranto & $52 \mathrm{v}-54 \mathrm{v}$ & $47 \mathrm{v}-50 \mathrm{r}$ & \\
\hline O passado me mata & $54 \mathrm{v}-56 \mathrm{r}$ & $50 \mathrm{r}-51 \mathrm{v}$ & \\
\hline Libre de aquel recelo & $56 \mathrm{v}-58 \mathrm{r}$ & $51 \mathrm{v}-53 \mathrm{v}$ & 38261 \\
\hline Em hum vale florido & $58 \mathrm{r}-60 \mathrm{r}$ & $53 \mathrm{v}-55 \mathrm{v}$ & \\
\hline Aqui se esconde a única beleza & $60 \mathrm{v}$ & $56 \mathrm{r}$ & \\
\hline Aqui repousa em terra transformado & $60 \mathrm{v}$ & $56 \mathrm{r}$ & \\
\hline Rico poeta que no ceo subido & $61 \mathrm{r}$ & $56 \mathrm{r}-56 \mathrm{v}$ & \\
\hline Em tanto que no vosso pensamento & $61 \mathrm{v}$ & $56 \mathrm{v}$ & \\
\hline Olhos que por vontade e por estrela & $61 \mathrm{v}$ & $56 \mathrm{v}-57 \mathrm{r}$ & \\
\hline Quem pretende colher fruto 141 & & $57 \mathrm{r}-57 \mathrm{v}$ & \\
\hline
\end{tabular}

141 Como puede comprobarse, este poema y los dos que siguen no figuran en el manuscrito, sino sólo en el impreso. Curiosamente, el corrector del mismo, Juan Vázquez del Mármol, se percató de esta ausencia porque no pudo corregir según el original; por eso realizó una pequeña marca, un asterisco, a la derecha de cada uno de los poemas ausentes en el manuscrito. 


\begin{tabular}{|l|l|l|l|}
\hline Que confiança terey & & $57 \mathrm{v}-58 \mathrm{r}$ & \\
\hline Triste de quem acordou & & $58 \mathrm{r}-58 \mathrm{v}$ & \\
\hline Senhor Pedro Bermudes pois a guerra & $62 \mathrm{r}-65 \mathrm{v}$ & & \\
\hline Ay cegos pemsamentos que enganada & $66 \mathrm{r}$ & $59 \mathrm{r}$ & \\
\hline $\begin{array}{l}\text { Desvelame meu mal que he muito } \\
\text { grande }\end{array}$ & $66 \mathrm{r}-66 \mathrm{v}$ & $59 \mathrm{r}-59 \mathrm{v}$ & \\
\hline $\begin{array}{l}\text { Quando me paro a contemplar mi } \\
\text { suerte }\end{array}$ & $66 \mathrm{v}$ & & \\
\hline O rremedio da morte he yusta vida & $67 \mathrm{r}$ & $59 \mathrm{v}$ & \\
\hline Aquele parecer cuya preçença & $67 \mathrm{r}-67 \mathrm{v}$ & & \\
\hline O estrema alegria o sonho leve & $67 \mathrm{v}$ & $60 \mathrm{r}$ & \\
\hline Sou branda sou cruel e sou fermosa & $68 \mathrm{r}$ & $60 \mathrm{v}$ & \\
\hline Quien es este mancebo atormentado & $68 \mathrm{v}$ & $61 \mathrm{r}-61 \mathrm{v}$ & 70167 \\
\hline Yo soy aquella miserable dama & $69 \mathrm{v}$ & $61 \mathrm{v}$ & 47030 \\
\hline Cuidar minha Florença neste aviso & $69 \mathrm{v}$ & $62 \mathrm{r}$ & \\
\hline Esperança lisongera & $70 \mathrm{r}-70 \mathrm{v}$ & $62 \mathrm{r}-63 \mathrm{r}$ & 69371 \\
\hline Deixando quantos estremos & $71 \mathrm{r}$ & $63 \mathrm{r}-63 \mathrm{v}$ & \\
\hline El amante consumido & $71 \mathrm{v}$ & $64 \mathrm{r}{ }^{142}$ & 69180 \\
\hline Vem alegre a primavera & $72 \mathrm{r}$ & $64 \mathrm{v}$ & \\
\hline Pretendeo a primavera & $72 \mathrm{r}-72 \mathrm{v}$ & $64 \mathrm{v}-65 \mathrm{r}$ & \\
\hline Nao queira minha ventura & {$[73 \mathrm{r}-73 \mathrm{v}]^{143}$} & $65 \mathrm{r}-65 \mathrm{v}$ & \\
\hline Ciego, picado y perdido & {$[73 \mathrm{v}]$} & $65 \mathrm{v}-$ & 72517 \\
& & {$[66 \mathrm{r}]$} & \\
\hline El momo tengo por vicio & {$[73 \mathrm{v}]$} & $65 \mathrm{v}-[66 \mathrm{r}]$ & 72518 \\
\hline Pois que vos prezais de amor & $74 \mathrm{r}$ & {$[66 \mathrm{r}-66 \mathrm{v}]$} & \\
\hline Assim o benino amor & $74 \mathrm{r}-74 \mathrm{v}$ & {$[66 \mathrm{v}]$} & \\
\hline Assi Deos o sufrimento & $74 \mathrm{v}-75 \mathrm{r}$ & {$[66 \mathrm{v}]-67 \mathrm{r}$} & \\
\hline Qual debe ser o cavalo & $75 \mathrm{r}$ & $67 \mathrm{r}-67 \mathrm{v}$ & \\
\hline Que se fez de Cartago escasamante & $75 \mathrm{v}-76 \mathrm{r}$ & $68 \mathrm{r}-68 \mathrm{v}$ & \\
\hline Pois me desenganou a confiança & $76 \mathrm{r}-76 \mathrm{v}$ & $69 \mathrm{r}-70 \mathrm{r}$ & \\
\hline Señor Pedraires hum estreito amigo & $76 \mathrm{v}-78 \mathrm{r}$ & $70 \mathrm{r}-71 \mathrm{v}$ & \\
\hline Pastora da serra & $78 \mathrm{r}$ & $72 \mathrm{r}-72 \mathrm{v}$ & \\
\hline Descobri meus sospiros a segredo & $78 \mathrm{v}$ & $72 \mathrm{v}$ & \\
\hline Ha sombra de tal árvore quem pode & $79 \mathrm{r}$ & $73 \mathrm{r}$ & \\
\hline Corre meu pensamento a rredea solta & $79 \mathrm{r}-79 \mathrm{v}$ & $73 \mathrm{r}-73 \mathrm{v}$ & \\
\hline Loures entrahas alma escolhidas & $79 \mathrm{v}$ & $73 \mathrm{v}-74 \mathrm{r}$ & \\
\hline & & & \\
\hline
\end{tabular}

${ }^{142}$ En la foliación del impreso hay una errata, y en vez de 64 aparece 46.

${ }^{143}$ Este es el folio que falta en el manuscrito, tal como vimos anteriormente. Vid. supra, p. 215.

${ }^{144}$ De nuevo vuelve a haber un error de foliación, 67 por 66 . El folio 67 está repetido. 


\begin{tabular}{|l|l|l|l|}
\hline Estranha presunçao carroças grauas & $79 \mathrm{v}-80 \mathrm{r}$ & $74 \mathrm{r}$ & \\
\hline Sepultura de vivos alma livre & $80 \mathrm{r}$ & $74 \mathrm{r}-74 \mathrm{v}$ & \\
\hline Triste gale estranho labarinto & $80 \mathrm{r}-80 \mathrm{v}$ & $74 \mathrm{v}-75 \mathrm{r}$ & \\
\hline Dizem que estando na presença hum dia & $80 \mathrm{v}$ & $75 \mathrm{r}$ & \\
\hline
\end{tabular}

\section{Edición de los sonetos inéditos en castellano}

Como colofón a nuestro trabajo, procedemos a editar los dos poemas en castellano que, aunque figuran en el códice de Días, no fueron seleccionados para figurar en el impreso y que, por lo tanto, han permanecido inéditos hasta el descubrimiento del manuscrito. Es complejo especular sobre cuáles pudieron ser las razones por las que no fueron seleccionados para la impresión; no obstante, teniendo en cuenta el contenido ideológico de los poemas, parece lógico apuntar a la censura inquisitorial, tal vez por ser su autor de origen converso ${ }^{145}$-algo muy frecuente en su ciudad natal, caso de ser Oporto- ${ }^{146}$, tal vez al hecho de que el poemario manuscrito se encuentre en la sección que alberga censuras literarias del Santo Oficio.

Cabe recordar que la obra de Días no aparece en ninguno de los índices de libros prohibidos y expurgados, ni en el de Sandoval y Rojas de $1612^{147}$, ni en ninguno de los posteriores ${ }^{18}$; pero precisamente tal ausencia se explica porque en estos poemas inéditos, hoy recuperados, podría haber motivos vituperables para que no figurasen en el impreso, de forma que el censor ${ }^{149}$, aunque validó su publicación, canceló algunos poemas por considerarlos poco adecuados. Así, por ejemplo, el primer poema inédito que editamos, el soneto Ya cerca de la muerte está la vida (fol. 13r), parece aludir al tema del suicidio, invocando directamente a Dios en el último verso para salvar al poeta de sus intenciones. En el caso del segundo poema que editamos, Quando me paro a contemplar mi suerte (fol. 66v), también utiliza como recurso retórico un apóstrofe dirigido directamente a la divinidad, posible explicación de su ausencia en el impreso. Ambos sonetos se encuentran tachados ${ }^{150}$, si bien se alcanzan a leer sin

$145 \mathrm{Si}$ bien hay varios personajes homónimos señalados como cristianos nuevos en algunos documentos inquisitoriales de la época, como sucede con un "Duarte Dias" a quien se refiere una confesión efectuada en 1594 por "Estevão Cordeiro, natural de Pôrto de Mós", o el mercader "Duarte Dias" y su mujer, "Florença Dias", padres del cristiano nuevo "natural da cidade do Pôrto Miguel Dias de Paz", confesante también en 1594. Cf. J. A. G. de Mello (1970), pp. 26-27 y 50-53, respectivamente. Otros personajes homónimos, asimismo señalados como criptojudíos en la época, parecen tener una conexión más compleja para considerarlos vinculados con nuestro autor. $C f$. M. J. P. Ferro Tavares (1992), pp. 205-207 y 340-341.

${ }^{146} C f$. I. S. Révah (1962), pp. 45-76.

147 Cf. S. Cabezas Fontanilla (2005), pp. 7-30.

${ }^{148} C f$. A. Márquez (1980), pp. 235-236.

149 Tal vez el mismo Pedro López de Montoya, que parece haberse ocupado de la censura de casi todos los libros poéticos impresos entre los años 1575 y 1596 . Véase el estudio de E. Hernández Rodríguez (1947).

${ }^{150}$ Sucede en otras partes del manuscrito, con poemas en portugués que tampoco figuran en la edición impresa: Acaso triste caminhando hum dia (fols. 3v-4r), De varios pensamentos 
problemas, buena prueba de que quien ejerciera la censura los marcó para que no fuesen incluidos entre las obras que sí poblarían la edición impresa de 1590.

En otras ocasiones, parece que algunos poemas sufrieron expurgos parciales de coplas que, presentes en el manuscrito, están tachadas y, por lo tanto, tampoco fueron impresas ${ }^{151}$. Por último, nos quedan algunos ejemplos de poemas completamente inaccesibles hoy día, pues se les ha pegado una hoja de papel encima para hacerlos desaparecer por completo de la vista, poemas que, como el lector adivinará, tampoco están en la edición impresa ${ }^{152}$. No obstante, la censura pudo deberse al mucho mayor control que, en líneas generales, impresores y censores tenían sobre la obra finalmente impresa que el propio autor ${ }^{153}$.

Queden estos dos ejemplos en castellano como prueba de las muchas sorpresas que su poemario manuscrito pudiera depararnos en el futuro, cuando sea más profundamente estudiado y podamos situar en el adecuado contexto de época filipina a un poeta portugués afincado en España que "tentou entender todas as contradições que existiam à época da sua escritura, incorporando-as, de maneira evidente, no seu tecido poético" 154

\section{[I] \\ SONETO ${ }^{155}$}

Ya cerca de la muerte está la vida ${ }^{156}$

y cerca de la vida estát ${ }^{157}$ el morir;

mi suerte no los quiere despartir:

antes, a que se abraçen los combida.

El alma, recelosa y afligida

combatido (fol. 9r), Pragentas almas que em mor desmetidas (fols. 14r-14v), Ó, rigurosa morte, ó, morte dura (fols. 18r-18v), Branca tumor da terra acor da rosa (fol. 25v), Cansado ya do sono em que deseanca (fol. $41 \mathrm{v}$ ), Bem se pode ver no pato (fol. 48r), el ya citado Discurso sobre as cousas dos soldados, protagonizado por Pedro Bermudes (fols. 62r-65v), y Aquele parecer cuya preçença (fols. 67r-67v).

${ }^{151}$ Es el caso, por ejemplo, de una estrofa, que comienza Se nao pretendo resistir a força (fol. 32v), perteneciente al poema Se hum desigual e cego pensamento (fols. 32r-32v). Otros casos quedan pendientes de ulterior análisis, que acometeremos más adelante para editar la poesía completa de Duarte Días, tal como pretendemos hacer en un futuro próximo.

${ }^{152}$ Lo que convertiría al manuscrito en un original de imprenta en fase 1, "firmado por el escribano, con posibles modificaciones emanadas de la censura", en palabras de J. M. Lucía Megías (2009), p. 196.

153 Seguimos la argumentación de J. L. Canet (2009), pp. 70-72.

${ }^{154}$ Hacemos nuestras las palabras de F. C. Lopes Junior (1993), p. 72.

155 Respetamos las grafías originales, aunque puntuamos y acentuamos conforme a los criterios actuales. Para cualquier explicación original recurrimos a la anotación a pie de página.

156 OR: la vida] En el manuscrito, estas dos palabras se encuentran agregadas posteriormente, sobre un papel que está pegado encima del texto original, como corrección del autor.

${ }^{157}$ OR: estaa] Se restaura la evidente errata del copista. 
(temiendo ya los daños por venir), para se reformar y arrepentir ${ }^{158}$, les ruega que dilaten su partida. Mas la vida, gastada de flaqueza, y la muerte, zelosa de acabarme,

y mi suerte, contraria de mis bienes, ninguno se conviene a escucharme; y anssí, cubierto de mortal tristeza, me parto, mi Señor, si tú no vienes.

[II]

SONETO

Quando me paro a contemplar mi suerte y a ver los trances por do me ha traído, hallo, según por dó anduve perdido, que me fuera mejor la dura muerte. Mas, quando quiere Dios que se despierte $e n^{159}$ más sano discurso mi sentido, $\operatorname{conosco}^{160}$ quánto fue mejor partido la vida, pues el alma se convierte ${ }^{161}$. Recibe Tú, hermosa y clara lumbre, de nuestra redención el tierno llanto, con humildes entrañas derramado: líbrame de los reinos del espanto y llévame, Señor, $a$ aquella ${ }^{122}$ cumbre para do ${ }^{163}$, por Tu mano, fui criado.

\section{OBRAS CITADAS}

AGUlLó Y COBO, Mercedes: "Datos para las biografías de escritores de los siglos XVI y XVII", Anales del Instituto de Estudios Madrileños, 4 (1969), pp. 169-231.

---: La imprenta y el comercio de libros en Madrid: (siglos XVI-XVIII), Tesis doctoral inédita, dir. José Simón Díaz, Madrid, Universidad Complutense, 1992.

${ }^{158}$ OR: arepentir] Enmendamos según el uso actual de la consonante doble.

159 OR: com] La preposición 'com' aparece tachada y corregida manuscritamente por el autor a "en”, lectura que respetamos por parecernos más adecuada.

160 conosco] reconozco.

161 OR: comvierte] Se corrige la grafía, muy probablemente causada porque el autor no pudo evitar que su origen luso le confundiera.

162 OR: haquella] Para hacer mejor sentido, se reconstruye la preposición aglutinada en el determinante, a pesar de que tales aglutinaciones eran todavía muy frecuentes en la poesía de la época.

${ }^{163}$ para do] para la que. 
ALVES, Hélio J. S.: "Um poeta quinhentista resurgido: a propósito das Várias Obras em Língua Portuguesa e Castellana de Duarte Días reeditadas por Antonio Cirurgião", Anais da Universidade de Évora, 3 (1993), pp. 99-109.

ANTONIO, Nicolás: Biblioteca Hispana Nova sive Hispanorum scriptorum qui ab anno 1500 ad 1684 floruere notitia, Roma, ex Officina Nicolai Angeli Tinassii, 1672.

---: Biblioteca Hispana Nova sive Hispanorum scriptorum qui ab anno 1500 ad 1684 floruere notitia, Matriti, Apud Joachinum de Ibarra Typographum Regium, 1783.

AQUILA, August J.: Alonso de Ercilla y Zúñiga: A Basic Bibliography, London, Grant and Cutler, 1975.

ARCE, Joaquín: Tasso y la poesía española. Repercusión literaria y confrontación lingüistica, Barcelona, Planeta, 1973.

ARES MONTES, José: "Duarte Dias, cantor de la conquista de Granada", Revista de Filología Románica, 2 (1984), pp. 19-36.

ASENSIO, Eugenio: "España en la épica filipina. Al margen de un libro de H. Cidade", Revista de Filología Española, 33 (1949), pp. 66-109.

BARANDA, Nieves: "Escritoras sin fronteras entre Portugal y España en el Siglo de Oro", Revista de Estudios Ibéricos, 2 (2005), pp. 219-236.

BARBolani Di MonTAUTO, Cristina: "Las traducciones al castellano de la Première Sepmaine de Du Bartas", en Imágenes de Francia en la letras hispánicas, coord. Francisco Lafarga Maduell, Barcelona, PPU, 1989, pp. 209-216.

Bouza Álvarez, Fernando: Portugal en la monarquía hispánica (1580-1640). Felipe II, las Cortes de Tomar y la génesis del Portugal católico, Madrid, Universidad Complutense, 1987.

---: "Para qué imprimir: De autores, público, impresores y manuscritos en el Siglo de Oro", Cuadernos de Historia Moderna, 18 (1997), pp. 31-50.

---: Imagen y propaganda: capitulos de historia cultural del reinado de Felipe II, Madrid, Akal, 1998.

---: Corre manuscrito. Una historia cultural del Siglo de Oro, Madrid, Marcial Pons, 2001.

---: “«No puedo leer nada.» El corrector general Juan Vázquez del Mármol y la cultura escrita del Siglo de Oro", Syntagma: revista de historia del libro y de la lectura, 0 (2002), pp. 19-45.

---: «El primer lector del Quijote», ABC de las Artes y las Letras, 846 (2008), pp. 4-7.

---: Felipe II y el Portugal dos povos. Imágenes de esperanza y revuelta, Valladolid, Universidad de Valladolid, 2010.

Braga, Theópilo: História dos Quinhentistas. Vida de Sá de Miranda e sua eschola, Porto, Imprensa Portugueza, 1871.

BRANDERBERGER, Tobías: "Antagonismos intraibéricos y literatura áurea. Algunas reflexiones metodológicas ejemplificadas", Iberoamericana, 28 (2007), pp. 79-97.

BRoOKS, Mary Elizabeth: "From Military Defeat to Inmortality: The Birth of Sebastianism", Luso-Brazilian Review, 1.2 (1964), pp. 41-49.

BUESCU, Ana Isabel: "Aspectos do bilinguismo portugês-castelhano na época moderna»", Hispania, 64.1 (2004), pp. 13-38. 
Bustos TÁULER, Álvaro: "Francisco de Terrazas, poeta toscano, latino y castellano", Dicenda. Cuadernos de Filología Hispánica, 21 (2003), pp. 5-19.

CABello PoRras, Gregorio: "Las Varias poesías (1591) de Hernando de Acuña: de Garcilaso a Boscán. El tránsito del humanismo militar a la 'nueva lengua poética'”, Dicenda. Cuadernos de Filología Hispánica, 5 (2008), pp. 5-61.

CABEZAS FONTANILla, Susana: "En torno a la impresión del «Catálogo de libros prohibidos y expurgados» de 1612", Documenta \& Instrumenta, 3 (2005), pp. 7 30.

CANET, José Luis: “Algunas reflexiones sobre el proceso de edición en el siglo XVI y la bibliografía textual", Edad de Oro, 28 (2009), pp. 59-72.

CARRASCO URGOITI, María Soledad: El moro de Granada en la literatura. (Del siglo XV al XX), Madrid, Revista de Occidente, 1989.

CARVAlHo, José Adriano de Freitas: "As ruínas na poesía portuguesa do século XVII. Uma antología breve", Revista da Faculdade de Letras, Lenguas e Literaturas, 20.1 (2003), pp. 34-46.

Catálogo de la Biblioteca del Excmo. Sr. D. Manuel Pérez de Guzmán y Boza, Marqués de Jerez de los Caballeros. Primera parte, Sevilla, 1898.

CHARTIER, Roger: "Le prince, la bibliothèque et la dedicace au XVIe et XVIIe siècles", en El libro antiguo español. III. El libro en palacio y otros estudios bibliográficos, eds. María Luisa López-Vidriero y Pedro M. Cátedra, Salamanca: Ediciones de la Universidad, 1996, pp. 81-100.

CHEVALIER, Maxime: L'Arioste en Espagne, 1530-1650: recherches sur l'influence $d u$ "Roland furieux", Bordeaux, Institut d'Études ibériques et ibéro-américaines, 1966.

CIRURGIão, António: A sextina em Portugal nos séculos XVI e XVII, Lisboa, Instituto de Cultura e Língua Portuguesa, 1992.

---: "Le merveilleux dans La conquête [...] du Royaume de Grenade de Duarte Dias", Arquivos do centro cultural Caslouste Gulbenkian, 44 (2002), pp. 85-99.

CorTe-Real, Jerónimo: Poesia, ed. Hélio J. S. Alves, Braga, Angelus Noves, 1998.

Cueto, Ronald: " 1580 and All That... Philip II and the Politics of the Portuguese Succession”, Portuguese Studies, 9 (1992), pp. 150-169.

DA SILVA, Innocéncio Francisco: Diccionario bibliographico portuguez, Lisboa, Imprensa Nacional, 1870.

DÁnVIla y Burguero, Alfonso: Don Cristóbal de Moura, primer Marqués de Castel Rodrigo (1538-1613), Madrid, Fortanet, 1900.

DiAS, Duarte: Várias Obras em Língua Portuguesa e Castelhana, introducción y notas de Antonio Cirurgião, París, Centro Cultural Portugués - Fundación Calouste Gulbenkian, 1991.

DÍAZ, Francisco: Tratado nuevamente impresso de todas las enfermedades de los riñones, vexiga y carnosidades de la verga y urina, Madrid: Francisco Sánchez, 1588. Edición facsímil Madrid, Eco, 1968.

ESCAPA, Pablo Andrés et al:: "El original de imprenta", en Imprenta y crítica textual en el Siglo de Oro, dir. Francisco Rico, Valladolid, Universidad de Valladolid, 2000, pp. 29-64. 
Ferro Tavares, María José Pimenta: Los judios en Portugal, Madrid: Mapfre, 1992.

GALlARDO, Bartolomé José: Ensayo de una biblioteca española de libros raros y curiosos, Madrid, Rivadeneyra, 1866.

GANDRA, Manuel J.: Joaquim de Fiore, Joaquimismo e Esperança Sebástica, Lisboa, Fundação Lusíada, 1999.

GARRIDO ATIENZA, Miguel: Las capitulaciones para la entrega de Granada, Granada, Paulino Ventura Traveset, 1910.

GARZA MERINO, Sonia: Manuscritos e imprenta, Tesis doctoral inédita, dir. Carlos Alvar, Alcalá de Henares, Universidad, 2005.

---: "Vida de San Gerónimo: el texto proceso de constitución”, Edad de Oro, 28 (2009), pp. 105-142.

GisBert TEROL, Ana, y María Lutgarda ORTElls PÉREZ: Catálogo de obras impresas en el siglo XVI de la Biblioteca General e Histórica de la Universitat de Valencia, Valencia, Conselleria de Cultura, Educació i Ciència, 1992.

GlASER, Edward: Estudios hispano-portugueses. Relaciones literarias del Siglo de Oro, Madrid, Castalia, 1957.

GÓMEZ VOZMEDIANO, Miguel F.: "El silencio de los inocentes. Ecos inquisitoriales en Madrid y su tierra durante el epígono Trastámara. Una aproximación prosopográfica", Cuadernos de Historia Moderna, 30 (2005), pp. 41-62.

GONZÁlEZ RolÁN, Tomás, y Pilar SAQUERO SUÁREZ-SOMONTE: "Sobre los avatares de la edición en el humanismo español: acercamiento a la actividad del granadino Juan Vázquez del Mármol como corrector general y crítico textual”, Cuadernos de Filología Clásica. Estudios latinos, 3 (1992), pp. 23-37.

Hermann, Jacqueline: No reino do desejado. A construção do sebastianismo em Portugal (séculos XVI e XVII), São Paulo, Companhia das Letras, 1998.

HERNÁNDEZ RoDRíGUEZ, Emilio: Las ideas pedagógicas del doctor Pedro López de Montoya, Madrid, CSIC, 1947.

INFANTES, Víctor: "«Como merece a gente Lusitana». La poesía sin fronteras del Livro de sonetos y octauas de diuersos auctores (1598)", Península. Revista de Estudos Ibéricos, 0 (2003), pp. 185-200.

LABRADOR ARroyo, Félix: La Casa Real portuguesa de Felipe II y Felipe III: la articulación del reino a través de la integración de las elites de poder (15801621), Tesis doctoral inédita, Madrid, Universidad Autónoma, 2006.

LaBrador Herraiz, José J., y Ralph A. DiFranco: Tabla de los principios de la poesía española, Cleveland, Cleveland State University, 1993.

---: Cancionero autógrafo de Pedro de Padilla (manuscrito 1579 de la Biblioteca Real de Madrid), México, Frente de Afirmación Hispanista, A.C., 2007.

LiÑÁn DE RIAZA, Pedro: Poesías, ed. Julian F. Randolph, Barcelona, Puvill, 1982.

LOHMANN VILLENA, Guillermo: "Enrique Garcés, descubridor del mercurio en el Perú, poeta y arbitrista", Anuario de estudios americanos, 5 (1948), pp. 439-482.

LOPES JÚNIOR, Francisco Caetano: "Review of Várias obras em língua portuguesa e castelhana, by Duarte Dias, ed. António Cirurgião", Hispania, 76.1 (1993), pp. 71-72. 
LUCÍA MEGÍAS, José Manuel: "El autor ante la imprenta: textos para un manual", Edad de Oro, 28 (2009), pp. 177-196.

MACHADO, Diogo Barbosa: Biblioteca Lusitana, Lisboa: Ignacio Rodrigues, 17411754,4 vols.

MAGANTO PAVÓN, Emilio: "Francisco Díaz (1527-1590), padre de la urología", Boletín del Colegio Mexicano de Urología, 10 (1993), pp. 3-12.

---: "La intervención del Dr. Francisco Díaz en el proceso inquisitorial contra Elena/O de Céspedes, una cirujana transexual condenada por la inquisición de Toledo en 1587”, Archivos Españoles de Urología, 60.8 (2007), pp. 873-886.

---: "«...es porque el tiempo es breve y no me atrevo a poder pagar lo que te debo» (o de la relación entre Miguel de Cervantes y el Doctor Francisco Díaz)", Anales Complutenses, 21 (2009), pp. 35-105.

MÁRQUEZ, Antonio: Literatura e Inquisición en España (1478-1834), Madrid, Taurus, 1980.

MARTíneZ HeRnÁNDEZ, Santiago: "En la Corte la ignorancia vive [...] y [...] son poetas todos. Mecenazgo, bibliofilia y comunicación literaria en la cultura aristocrática de corte", Cuadernos de Historia Moderna, 35 (2010), pp. 35-67.

Mello, José Antonio Gonsalves de: Confissões de Pernambuco, 1594-1595, Recife, Universidade Federal de Pernambuco, 1970.

Norton, Frederick J.: A Descriptive Catalogue of Printing in Spain and Portugal, 1501-1520, Cambridge, University Press, 1978.

NúÑEZ, Duarte: Genealogía verdadera de los Reyes de Portugal con sus elogios y summario de sus vidas, Lisboa, Imprenta de Antonio Álvarez, 1590.

NúÑEZ, Valentín: "Los poemarios líricos en el Siglo de Oro: disposición y sentido", Philologia Hispalensis, 11 (1996-1997), pp. 153-166.

OLMEDILLA HERRERO, Carmen: "La ciencia paleográfica hispano-latina en el siglo XVI: edición y valoración de las Abreviaturas de Juan Vázquez del Mármol", Cuadernos de Filología Clásica. Estudios latinos, 4 (1993), pp. 191-232.

OSÓRIO, João de Castro: Florilegio das poesias portuguesas escritas em castelhano e restituidas à lingua nacional, Lisboa, Editorial Império, 1942.

PADILlA, Pedro: Thesoro de varias poesías, eds. José Labrador y Ralph DiFranco, prólogo de Aurelio Valladares, México, Frente de Afirmación Hispanista, 2008.

PAYNE, John Thomas, y Henry Foss: Bibliotheca Grenvilliana, or Bibliographical Notices of Rare and Curious Books Forming Part of the Right Hon. Thomas Grenville, London, Shakspeare Press, 1842.

PAZ Y Melia, Antonio: Catálogo abreviado de papeles de la Inquisición, Madrid, Tipografía de la Revista de Archivos y Bibliotecas, 1914.

PEDRAZA GRACIA, Manuel José: "La imprenta zaragozana del impresor Pedro Bernuz a través de los protocolos del notario Pedro Bernuz II", Revista de Historia Jerónimo Zurita, 72 (1997), pp. 29-52.

PenNeY, Clara Louisa: Printed Books 1468-1700 in the Hispanic Society of America, New York, Hispanic Society of America, 1965. 
PERES, Domingo Garcia: Catálogo razonado biográfico y bibliográfico de los autores portugueses que escribieron en castellano, Madrid, Imprenta del Colegio Nacional de Sordomudos y de Ciegos, 1890.

PÉREZ LÓPEZ, José Luis: "Una hipótesis sobre el Don Quijote de Avellaneda: De Liñán de Riaza a Lope de Vega", Lemir, 9 (2005), pp. 1-60.

PÉREZ PASTOR, Cristóbal: Bibliografía madrileña, o descripción de las obras impresas en Madrid (Siglo XVI), Madrid, Tipografía de los Huérfanos, 1891.

PIERCE, Frank: Alonso de Ercilla y Zúñiga, Amsterdam, Rodopi, 1984.

QUEROL COLL, Enric: "«La consolació corporal i temporal del poble»: pervivència del teatre a la ciutat de Tortosa en els segles XVI-XVIII", en El teatre català dels origens al segle XVIII, ed. Alberto Rossich et al., Kassel, Reichenberger, 2001, pp. 293-312.

RÉVAH, Israel S.: "La religion d'Uriel da Costa, marrane de Porto (d'après des documents inédits)", Revue de l'histoire des religions, 161.1 (1962), pp. 45-76.

RIVERO, Carlos del: Historia de la imprenta en Madrid, Madrid, Artes Gráficas Municipales, 1935.

RODRÍGUEZ-MOÑINO, Antonio: "El Alférez Francisco de Segura, autor y colector de romances", Revista del Instituto «José Cornide» de Estudios Coruñeses, 4 (1968a), pp. 185-204.

---: Construcción crítica y realidad histórica en la poesía española de los siglos XVI y XVII, Madrid, Castalia, 1968b.

RÖSNNER, Michael: “¿América como exilio para los valores caballerescos?: apuntes sobre la Numancia de Cervantes, la Araucana de Ercilla y algunos textos americanos en torno al 1600", en Actas del XII Congreso de la Asociación Internacional de Hispanistas, coord. Jules Whicker, Birmingham, University Press, 1998, III, pp. 194-203. Acceso directo en Internet a través de: $<\mathrm{http} / /$ cvc.cervantes.es/obref/aih/pdf/12/aih 123 027.pdf>

Salvá y Mallen, Pedro: Catálogo de la Biblioteca de Salvá, Valencia, Imprenta de Ferrer de Orga, 1872.

SÁNCHEZ, Juan Manuel: Bibliografía aragonesa del siglo XVI, Madrid, Imprenta Clásica Española, 1914.

SÁNCHEZ MARTÍNEZ, Francisco Javier: Historia y crítica de la poesía lírica culta "a lo divino" en la España del siglo de oro. 2.- Poemas en arte mayor y otras manifestaciones, Alicante, Edición del autor, 1999.

SÁNCHEZ PORTERO, Antonio: "El 'toledano' Pedro Liñán de Riaza - candidato a sustituir a Avellaneda- es aragonés, de Calatayud", Lemir, 11 (2007), pp. 61-78.

SARAIVA, António José, y Óscar LoPES: História da Literatura Portuguesa, Oporto: Porto Editora, 1973.

SEguRA, Francisco de: Romancero historiado. Trata de los hazañosos hechos de los Cristianísimos Reyes de Portugal, Lisboa, Imprenta de Vicente Álvarez, 1610.

SERRÃO, Joaquim Veríssimo: O Tempo dos Filipes em Portugal e no Brasil (15801668), Lisboa, Edições Colibrí, 1994.

SEVILla ARROYO, Florencia: "La intervención de la imprenta en el texto del tercer Quijote de Cuesta (1608)", Edad de Oro, 28 (2009), pp. 359-400. 
TICKNOR, George: Historia de la literatura española, trad. y ed. Pascual de Gayangos y Enrique de Vedia, Madrid, Rivadeneyra, 1854.

URREA, Jesús: Arquitectura y nobleza: casas y palacios de Valladolid, Valladolid, IV Centenario Ciudad de Valladolid, 1996.

Valladares Reguero, Aurelio: El poeta linarense Pedro de Padilla. Estudio biobibliográfico y crítico, Jaén, UNED, 1995.

VASCONCELOS, Carolina Michaëlis de: "Pedro de Andrade Caminha: beiträge zu seinem leben und wirken, auf grund un im anschluss an die neuausgabe des Dr. Josef Priebsch", Revue Hispanique, 8 (1901), pp. 338-450.

VeLÁZQUEZ, Isidoro: La entrada que en el Reino de Portugal hizo la S.C.R.M. de don Philippe, Invictíssimo Rey de las Españas, Lisboa, Manuel de Lyra a costa de Simón López, 1583.

VILÀ, Lara: "La épica española del Renacimiento (1540-1605): propuestas para una revisión”, Boletín de la Real Academia Española, 83 (2003), pp. 137-150.

---: "Actium y Lepanto en la épica española del XVI: la Felicísima victoria de Jerónimo Corte Real", Salina: revista de lletres, 18 (2004), pp. 75-90.

---: "Épica culta", en Diccionario filológico de Literatura española, siglo XVI, dir. Pablo Jauralde, Madrid, Castalia, 2009.

Villacorta BaÑos-García, Antonio: Don Sebastián, Rey de Portugal, Barcelona, Ariel, 2001.

VITERBO, Francisco Marques Sousa: "Tres poetas portuguezes desconhecidos", $O$ Instituto. Revista Scientifica e Litteraria, 47 (1900), pp. 694-696.

VoIGT, Lisa: "Imperial Celebrations. Local Triumphs: The Rhetoric of Festival Accounts in the Portuguese Empire", Hispanic Review, 79.1 (2011), pp. 17-41.

VV. AA: O Sebastianismo. Política, Doutrina e Mito (Sécs. XVI-XIX), Lisboa, Edições Colibrí - Academia Portuguesa de Història, 2004.

YMHOFF CABRERA, Jesús: Catálogo de los impresos europeos del siglo XVI que custodia la Biblioteca Nacional de México, México, Universidad Nacional Autónoma de México, 1996. 